Patterns and causes of oviposition in monarch butterflies:

implications for milkweed restoration

by

Grace Pitman

\author{
A Thesis \\ presented to \\ The University of Guelph
}

In partial fulfillment of requirements

for the degree of

Master of Science

in

Integrative Biology

Guelph, Ontario, Canada

(C) Grace Pitman, May, 2017 


\section{PATTERNS AND CAUSES OF OVIPOSITION IN MONARCH BUTTERFLIES: IMPLICATIONS FOR MILKWEED RESTORATION}

\section{Grace Pitman} University of Guelph, 2017
Advisor:

D. Ryan Norris

Effective habitat restoration requires an understanding of species habitat preferences and the associated mechanisms driving those preferences. We examined the patterns and causes of oviposition preference in the monarch butterfly, a rapidly declining species, in southwestern Ontario at multiple spatial scales. Oviposition preference was dependent on both the size and density of the milkweed patch, as well as landscape type. Small $\left(<16 \mathrm{~m}^{2}\right)$, low-density $(0-2$ milkweed per $\mathrm{m}^{2}$ ) milkweed patches in agricultural landscape had the highest egg density compared to all types of milkweed patches in non-agricultural and roadside landscapes. Mediumsized patches had the highest predator abundance. Variation in the diversity of predators and parasitoids, abundance of parasitoids, and occurrence of parasites of monarch eggs and larvae did not appear to coincide with preferred egg laying habitats. Our results have important implications for restoring milkweed as an approach to counteract monarch butterflies declines. 


\section{ACKNOWLEDGEMENTS}

This work was supported by Syngenta Canada Inc. and the ENGAGE and Discovery Grants from the Natural Sciences and Engineering Council. A Wildlife Scientific Collector's Authorization was obtained from the Ministry of Natural Resources (1079985) in order to collect monarchs. In addition, a research permit to conduct fieldwork on Nature Conservancy of Canada (NCC) land was obtained (AG-ON-2015-149612).

I would like to thank my advisor, Ryan Norris, for his substantial guidance and support to this project, and for providing this tremendous learning opportunity. I would also like to thank my advisory committee, Gard Otis and Alex Smith, for their helpful advice and support over the last two years. Tyler Flockhart provided considerable support and advice through all stages of this project.

My time during my masters was substantially enriched by the support of Norris lab mates, and WiP group members (Norris, Newman, McAdam, and Fryxell labs). I would especially like to thank my office mates, Danielle Ethier, Alex Sutton, Sam Knight, and Alana Wilcox for their friendship and unwavering support. I would like to extend my gratitude towards Brad Woodworth and Gustavo Betini who helped with analyses when all hope seemed lost.

At Bird Studies Canada I would like to thank Stuart Mackenzie, Myles Falconer, and Jon McCracken for aiding with field logistics. At the Long Point Bird Observatory I would like to thank Mark Conboy, and visiting researchers and volunteers who made my time in the field enjoyable. Fieldwork was made possible by the dedication of field assistants Anjuli Dabydeen, Aaron Drost, and Matthew Macpherson. Field volunteers, Caroline Gabani and Blair Fitz-gerald, time was greatly appreciated. I would also like to thank Ellen Richards and Kaelin Carbonetto who assisted with invertebrate predator and parasitoid identification. At Syngenta, I'd like to 
thank Paul Hoekstra for providing agricultural field logistics, and Brian Woolley, Patricia Kloepfer, and Marijke Van Andel for field scouting and contacting landowners. I would also like to thank the Nature Conservancy of Canada for allowing me to conduct research on their properties and for having many properties with milkweed available.

Lastly, I would like to thank my family and friends for their endless support and encouragement, especially my parents, Toni and Robin Pitman, and Shane Carr, who never tired of me talking of monarchs and milkweed. 


\section{TABLE OF CONTENTS}

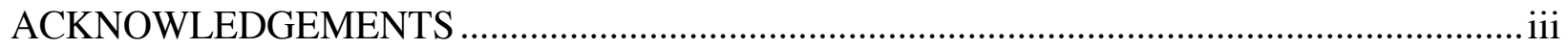

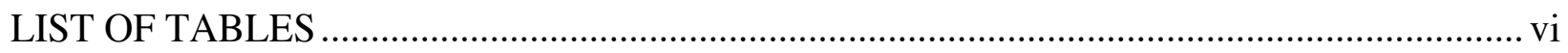

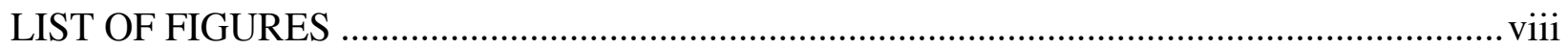

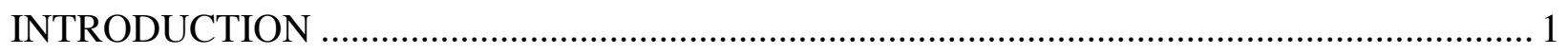

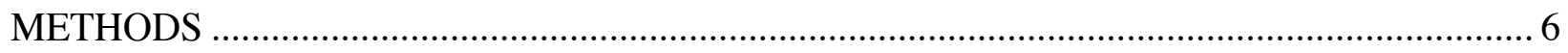

Study sites \& experimental design ....................................................................................... 6

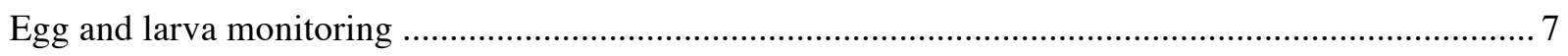

Invertebrate predator and parasitoid abundance and diversity ........................................................... 8

Parasitism of fifth instars ..................................................................................................... 9

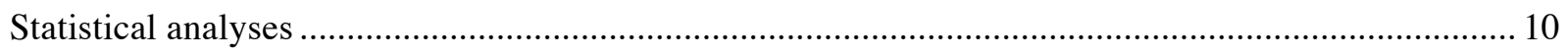

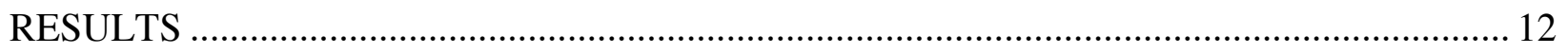

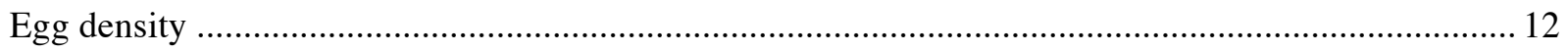

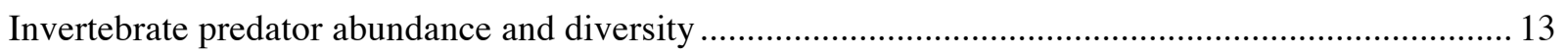

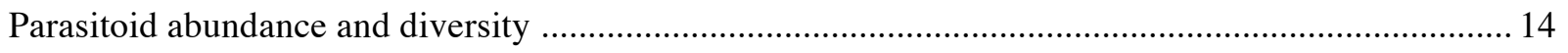

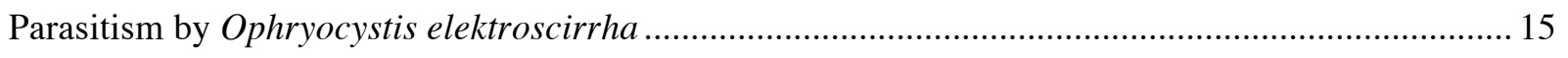

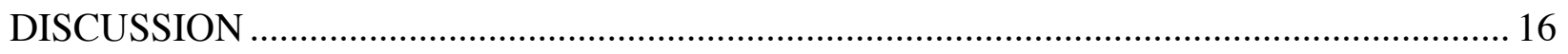

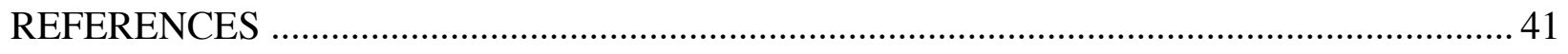

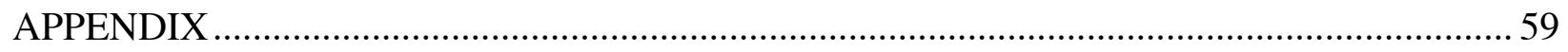




\section{LIST OF TABLES}

Table 1. Number of monitored milkweed patches in each size category, by landscape type over 6-week periods in both 2015 and 2016.

Table 2. Parameter estimates from the top mixed effects generalized linear model (based on AIC model selection, see Table A-1) to explain egg density based on landscape type, Julian date, year, patch size, milkweed density, and patch ID. Note the intercept value represents the predicted egg density in large agricultural patches. We report $95 \%$ confidence intervals. " * ' represents parameters that do not overlap with zero.

Table 3. Summary of the number of samples collected for invertebrate predator and parasitoid abundance and diversity sampling for each milkweed patch size and landscape type. Sampling was conducted every other week with a given patch being sampled a maximum of 3 times over the total 6 -week period.

Table 4. Mean and total number (in brackets) of individual invertebrate predators and parasitoids by family per pan trap sample. * represents families that included both adults and larval stages.

Table 5. Parameter estimates from the top mixed effects generalized linear model to explain invertebrate predator abundance based on Julian date, year, patch size, and patch ID (based on AIC model selection, see Table A-2). Note the intercept value represents the predicted predator abundance in large patches. We report $95 \%$ confidence intervals. ' * ' represents parameters that do not overlap with zero.

Table 6. Parameter estimates from the top mixed effects generalized linear model to explain parasitoid abundance based on landscape type, Julian date, year, and patch ID (based on AIC model selection, see Table A-4). Note the intercept value represents the predicted predator abundance in agricultural landscapes. We report 95\% confidence intervals. ' * ' represents parameters that do not overlap with zero. 
Table 7. Infection rate of Ophryocystis elektroscirrha (OE), a protozoan parasite, from adults eclosing from collected 5th instars originating from different landscape types. The parasite loads classified on a binary scale, with 0-3 $(0-100$ spores $)=$ moderate to no infection, and score 4-5 (>100) = heavily infected. 


\section{LIST OF FIGURES}

Figure 1. Map of study area showing field site locations colour coded by landscape type and the location of the study area within Ontario, Canada (red box in the inset map).

Figure 2. Milkweed density (total number of milkweed stems divided by the total area of the patch) in patches of milkweed each landscape type (agriculture: $n=330$; nonagriculture: $n=162$; roadside: $n=170$ ). Outliers not shown (see fig. A-2). Box and whiskers plot are composed of lower and higher quartiles (boxes), non-outlier ranges (whiskers), and medians (middle lines).

Figure 3. Predicted egg density (eggs/milkweed stem) in three landscape types (A, agriculture; B, non-agriculture; C, roadside) by patch size and milkweed density (milkweed stem $/ \mathrm{m}^{2}$ ) predicted from parameter estimates from the top model. Adjacent to each panel figure is a photographic example of a site in each associated landscape type.

Figure 4. Invertebrate predator abundance (number of predators per trap sampled every other week) per each patch size and landscape type (agriculture, non-agriculture, roadside). Outliers not shown (see fig. A-3). Box and whiskers plot are composed of lower and higher quartiles (boxes), non-outlier ranges (whiskers), and medians (middle lines).

Figure 5. Invertebrate predator diversity (number of predator families present per trap sampled every other week) per each patch size and landscape type (agriculture, non-agriculture, roadside). Box and whiskers plots are composed of non-outlier ranges (whiskers), lower and higher quartiles (boxes) and medians (middle lines). Outliers are represented as dots.

Figure 6. Parasitoid abundance (number of parasitoids per trap sampled every other week) per each patch size and landscape type (agriculture, non-agriculture, roadside). Outliers not shown (see fig. A-4). Box and whiskers plot are composed of lower and higher quartiles (boxes), non-outlier ranges (whiskers), and medians (middle lines). 
Figure 7. Parasitoid diversity (number of parasitoid families present per trap sampled every other week) per each patch size and landscape type (agriculture, non-agriculture, roadside). Box and whiskers plots are composed of non-outlier ranges (whiskers), lower and higher quartiles (boxes) and medians (middle lines). Outliers are represented as dots. 


\section{INTRODUCTION}

Habitat loss is one of the leading causes of species decline and extinction worldwide (Wilcove et al. 1998; Pimm and Raven 2000; Ceballos and Ehrlich 2002; Kerr and Cihlar 2004; Venter et al. 2006). Although not applicable to all species, one way to mitigate the negative effects of habitat loss is through active habitat restoration (Kareiva and Wennergren 1995; Fahrig 1997; Wisdom et al. 2002). However, realizing optimal gains in restoring habitat requires detailed and accurate knowledge of species habitat preferences. It is well known that organisms make decisions about where to settle based on multiple spatial scales, from landscapes to microenvironments, with the organism relying on different cues to identify a suitable site (Johnson 1980). Even if it is known what type of habitat a species prefers and at what spatial scale (Åström et al. 2013; Camaclang et al. 2015; Foit et al. 2016), the spatial configuration of the habitat can also influence settlement patterns (Pulliam et al. 1992; Lewis et al. 1996; Huxel and Hastings 1999). For example, patch area (Freemark and Merriam 1986; Davis 2004; Winter et al. 2006), patch shape (Davis 2004; Weldon and Haddad 2005), connectivity (Schadt et al. 2002; O'Brien et al. 2006), fragmentation (Hunter et al. 1995; Pereboom et al. 2008), and habitat heterogeneity (Freemark and Merriam 1986; Hunter et al. 1995; Heikkinen et al. 2004) have all been shown to influence individual success (Bergin et al. 2000; Misenhelter and Rotenberry 2000; DeCesare et al. 2014) and, in some cases, settlement preferences. Additionally, the preference of a species for particular habitat or habitat feature can also depend on the larger spatial scale in which it exists (Mazerolle and Villard 1999; Boyce et al. 2003; Quevedo et al. 2006; Mayor et al. 2009). For instance, the preference of the monarch flycatcher, 'elepaio (Chasiempis sandwichen) for ground cover measured on a fine scale ( $1.5 \mathrm{~m}$ radius), differed depending on whether the habitat was disturbed 
by human activities or undisturbed (VanderWerf 1993). Knowledge of what factors can influence species habitat preferences is important for effective restoration.

The eastern North American population of monarch butterflies (Danaus plexippus L.; Lepidoptera: Danainae) has declined by 95\% in the last 20 years (Brower et al. 2012) and the population is at a high risk of extirpation (Semmens et al. 2016). Butterflies of the last generation of the summer migrate up to $4000 \mathrm{~km}$ to the overwintering sites in central Mexico where they and congregate in massive clusters in oyamel fir (Abies religiosa) forests (Urquhart and Urquhart 1976; Brower 1996). In the spring, the same individuals migrate north to breeding grounds, mate, and over successive generations that follow, repopulate northern areas (Cockrell et al. 1993; Malcolm et al. 1993; Miller et al. 2012; Flockhart et al. 2013). Summer breeding individuals that live for 2-5 weeks travel comparatively shorter distances in search of nectar, mates, and egglaying locations (Oberhauser 2004). Monarchs oviposit - lay their eggs - exclusively on milkweeds of the subfamily Asclepiadoideae (milkweeds), typically singly on the undersides of leaves (Urquhart, 1960) and most commonly one per plant (Zalucki and Kitching 1982a). Milkweed provides both food and a chemical defense for the developing larvae (Parson 1965; Rothschild et al. 1966).

While a number of factors have been proposed for the population decline of monarchs, recent population models have shown that monarch abundance is more sensitive to the decline of milkweed, the obligate larval host plant, on the breeding grounds compared to deforestation or rising temperatures on the overwintering grounds in Mexico (Flockhart et al. 2015; Semmens et al. 2016 but see Inamine et al. 2016). The most significant reduction of milkweed has occurred in agricultural fields due to the use of glyphosate herbicides to kill weeds (Pleasants and Oberhauser 2013). The increase in the use of glyphosate herbicides follows the adoption of 
genetically modified (GM) crops, notably corn and soybean, altered to be glyphosate-tolerant (Padgette et al. 1996; Duke and Powles 2008). This has reduced the number of milkweed in North America, most severely in the central midwestern United States (Hartzler 2010; Pleasants and Oberhauser 2013; Pleasants 2017), a significant region of monarch production (Wassenaar and Hobson 1998; Oberhauser et al. 2001; Pleasants and Oberhauser 2013, Flockhart et al. 2017). For example, one study estimated that the 2.2 billion milkweeds present on the landscape in the central Midwest in 1999 had declined by almost 40\% by 2014 (Pleasants 2017). Another study estimated changes in agricultural weed management in Illinois led to an estimated $68 \%$ loss of available milkweed for monarchs in the last two decades (Zaya et al. 2017). To counteract the loss of milkweed on the breeding grounds, habitats could be restored to increase the availability of egg laying sites. Thus, it is imperative to understand the causes of monarch butterfly oviposition preference in different landscapes and spatial configurations to determine the most effective restoration strategy on the breeding grounds.

To date, studies examining female preferences for oviposition sites have largely consisted of counting eggs and larvae on milkweed in agricultural and non-agricultural landscapes (Oberhauser et al. 2001; Pleasants and Oberhauser 2013; Kasten et al. 2016). Agricultural landscapes have been shown to contain a higher number of eggs per plant than non-agricultural landscapes (Oberhauser et al. 2001; Pleasants and Oberhauser 2013). Roadsides, previously categorized as non-agricultural landscape with natural areas, have been proposed as a potentially suitable area for milkweed restoration due to the abundance of roads and availability of land on road margins (Hartzler and Buhler 2000, Taylor and Shields 2000, Oberhauser et al. 2001, Hartzler 2010, Pleasants and Oberhauser 2013). However, a recent study showed that roadsides have significantly lower egg per plant densities than non-agricultural areas, which included 
gardens, natural areas, pastures, and old fields (Kasten et al. 2016). There has yet to be a comprehensive study to compare all landscapes concurrently in the same region.

In addition, the mechanisms driving the oviposition preference between landscapes are not well understood. Females may prefer to oviposit in agricultural landscapes over nonagricultural landscapes and roadsides because agricultural landscapes may have fewer invertebrate predators. This pattern could arise from the use of agro-chemicals, specifically insecticides targeted to kill insects, as well as herbicides, which could reduce habitat for invertebrate predators. Conversely, females may prefer non-agricultural landscapes to oviposit due to the greater availability of nectar sources, which may lead to lower foraging times, better body condition and, ultimately, a larger number of eggs laid.

Monarch oviposition preference could also be influenced by the spatial configuration of habitat, such as the size or density of the milkweed patch. Low-density milkweed patches and single individual milkweed plants have been shown to contain a higher number of eggs per plant than high-density milkweed patches both in agricultural fields (Oberhauser et al. 2001; Pleasants and Oberhauser 2013) and in natural areas (Zalucki and Kitching 1982a, Zalucki and Suzuki 1987). However, this pattern in natural areas has only been shown in Australia where monarchs have been introduced and breed year-round in some regions, and it is not known whether the same pattern would occur in the eastern North American population in a different ecosystem containing of different milkweed species. While valuable, these studies also do not explain the possible mechanisms behind these patterns. Females may seek small milkweed patches to avoid natural enemies because large patches may be easier for predators, parasitoids, and parasites to find and could support their populations better than a smaller patch (Zalucki and Kitching 1982b). A protozoan parasite that monarchs are susceptible to is Ophryocystis elektroscirrha 
(OE), which in heavily infected individuals can result in short adult lifespans, reduced body size, lower mating success and decreased flight ability (Altizer and Oberhauser 1999; De Roode et al. 2007). The occurrence of $\mathrm{OE}$ in monarchs has not been examined in relation to the size of the milkweed patch they inhabit. The rate of $\mathrm{OE}$ infection in monarchs could be higher in larger milkweed patches that are frequented by more adult butterflies, potentially increasing the spread of $\mathrm{OE}$ to other adults or to milkweed leaves. Investigating which features in the landscape drive oviposition selection could help guide where restoration efforts should be focused.

Here, we examined the factors that drive monarch butterfly oviposition preference by monitoring the number of eggs and larvae in different landscapes (agricultural, non-agricultural, and roadsides) in patches of milkweed of varying sizes and densities, and by measuring the abundance and diversity of invertebrate predators and parasitoids and the occurrence of the protozoan parasite, $\mathrm{OE}$, in adults that emerged from collected fifth instars. Our hypotheses were considered at two spatial levels: the 'landscape' and 'patch' level. At the landscape level, following previous literature that suggests that agricultural landscape contains a higher number of eggs per plant than non-agricultural landscape (Oberhauser et al. 2001; Pleasants and Oberhauser 2013) due to lower abundance and diversity of invertebrate predators, parasites, and parasitoids, we predicted that egg densities would be higher in agricultural landscape compared to non-agricultural landscape and roadsides. Following this same hypothesis, we also predicted that invertebrate predators, parasitoids, and rate of OE infection would be lowest in agricultural landscapes and highest in non-agricultural landscapes due to reduced vegetation and use of agrochemicals. At the patch level, prior evidence suggests that low-density patches, single and small milkweed patches, contain higher egg densities than high-density milkweed patches in both agricultural fields (Oberhauser et al. 2001; Pleasants and Oberhauser 2013) and natural areas 
(Zalucki and Suzuki 1987) due to fewer predators, parasitoids, and parasites locating and breeding in small and low-density patches. Thus, we predicted that number of eggs per milkweed would be negatively related (i) to milkweed density in a patch and (ii) to patch size, as measured by monitoring milkweed patches of different sizes and densities in different landscape types. In addition, we predicted that estimated abundance and diversity of invertebrate predators and parasitoids, as well as the rate of infection of $\mathrm{OE}$, would be positively related to milkweed density in a patch and to patch size.

\section{METHODS}

\section{Study sites \& experimental design}

We conducted our study from Jul 13-Aug 21 2015, Jul 11-Aug 192016 in Norfolk, Oxford, and Brant Counties in southwestern Ontario, Canada (Fig. 1). The focal area, Norfolk County, borders the north shore of Lake Erie, which is a major migration pathway for monarchs (Gibo and Pallett 1979; Brower 1995). Study sites ( $\mathrm{n}=26$ total; 2015: $\mathrm{n}=7 ; 2016: \mathrm{n}=19)$ were located in one of three landscape types based on land use: agricultural crop fields $(\mathrm{n}=8$ total; 2015: $\mathrm{n}=3 ; 2016: \mathrm{n}=5)$, non-agricultural fields $(\mathrm{n}=9$ total; 2015: $\mathrm{n}=1 ; 2016: \mathrm{n}=8)$, and roadsides ( $n=9$ total; 2015: $n=3 ; 2016: n=6)$. Agricultural fields contained either corn or soybean crops and landowners were contacted through Syngenta Canada. Non-agricultural fields consisted of restored meadows $(n=6)$ and private gardens and lawns $(n=3)$. Roadside sites were stretches of public land in between roadways (county highways, regional, and municipal roads) and property borders (agricultural, natural, and residential). At each site there could be multiple milkweed patches (number of patches per site: mean $=4$, range $=1-21$ ). 


\section{Egg and larva monitoring}

In both years, we counted eggs and larvae by checking and counting all milkweeds in a patch for all sites during the breeding season (Jul 11 - Aug 21). To maximize the number of observations without double counting eggs or missing larvae, milkweed patches $(n=111$ total; 2015 : $n=43$; 2016; $n=68$ ) were checked for eggs and larvae every 7 d (Prysby 2004). Monarch larvae hatch 4-6 d after oviposition and have five instars, with each instar lasting from 2-5 d depending on ambient temperature (Zalucki 1982). The fifth instar pupates into a chrysalis from which the adult will eclose 9-14 d later (Zalucki 1982). Larval instars were identified by measuring the head capsule and tentacle lengths with a ruler (Oberhauser and Kuda 1997). 'Egg density' at a given site was calculated by the number of eggs counted divided by the total number of milkweeds checked. A milkweed patch was defined by a cluster of milkweed stems that were at least $10 \mathrm{~m}$ away from any other surrounding milkweed stems (hereafter referred to as 'milkweed; Matter 1996). Milkweed 'patch size' $\left(\mathrm{m}^{2}\right)$ was measured by either using a $1 \mathrm{~m}^{2}$ sampling quadrat or by walking the perimeter of the clustered stems using a Global Positioning System (GPS GPSMAP 64st model $\pm 5 \mathrm{~m}$ accuracy; Hartzler 2010). Single stems were assigned a patch size of $1 \mathrm{~m}^{2}$ (Hartzler and Buhler 2000). Milkweed density within a patch, referred to from here on as 'milkweed density', was calculated as the number of individual stems divided by the total area of the patch. To determine milkweed density in a patch, an individual milkweed stem was defined as any stem that was separated from another stem of the same milkweed species by soil (Kasten et al. 2016). The area and milkweed density of the patch was measured each time eggs were counted (every $7 \mathrm{~d}$ ) to have an accurate representation of the patch area and milkweed density at the time of oviposition because milkweed plants may have emerged or died over time. 
Patch size was recorded as a continuous variable but there was some evidence that some landscape categories had mostly small (e.g. agriculture) or large (e.g. non-agriculture) patch sizes (Figure A-1). To capture this variation in patch area across landscapes we conducted an initial analysis to determine discrete patch size categories to ensure that we had sufficient sample sizes for each landscape. To do so, we used a GLMM to explain egg density using Julian date, year (2015, 2016), and landscape type (agricultural, non-agricultural, roadside), which included the number of plants checked as an offset. Patch ID was included as a random effect because the same patches were checked each week over the breeding season. The model was then iterated to cycle through all possible patch area combinations among three patch sizes (small, medium and large). We recorded the AIC (Akaike Information Criterion; Burnham and Anderson, 2002) value of each model iteration and then used the size categories reported in the model with the lowest AIC value. From this preliminary analysis, the patch size categories were determined to be 'small' 1-15 $\mathrm{m}^{2}$, 'medium' 16-28 $\mathrm{m}^{2}$, and 'large' 29-472 $\mathrm{m}^{2}$ and were used in all further statistical models (Table 1; see Statistical Analysis, below).

\section{Invertebrate predator and parasitoid abundance and diversity}

The abundance of invertebrate predators and parasitoids was estimated using pan traps that were placed inside $86(2015: \mathrm{n}=18 ; 2016: \mathrm{n}=68)$ of 111 monitored milkweed patches. Standard yellow insect pan traps were used because they have been shown to attract the widest diversity of insects (Kirk 1984) and monarch eggs and larvae are known to be subject to an array of invertebrate predators and parasitoids (Oberhauser et al. 2015). Predators include lacewing larvae (Chrysopidae; Oberhauser et al. 2015), lady beetles (Coccinellidae; Koch et al. 2003; Koch et al. 2005), true bugs (Hemiptera; Zalucki and Kitching 1982b; De Anda and Oberhauser 2015), ants (Formicidae; Calvert 2004; Prysby 2004) and paper wasps (Vespidae; Rayor 2004; 
Oberhauser et al.2015). Monarchs are also susceptible to parasitism by parasitoid Hymenoptera (Oberhauser et al. 2015; Stenoien et al. 2015) and tachinid flies (Tachinidae; Arnaud 1978; Borkin 1982; Oberhauser et al. 2012). The traps were placed such that they were flush with the soil surface and filled halfway with a solution made with 4 teaspoons of salt and 5 drops of unscented dishwashing detergent per litre of water. Pan traps were placed in a patch for 48 hrs, then reinstalled every week in 2015 or every other week in 2016. Data collected in 2015 were censored to only include samples from every other week to be consistent with 2016 sampling. The contents of each pan trap were strained, rinsed, and put into a glass vial containing $75 \%$ ethanol. All invertebrates were identified to family level or below in the laboratory using a microscope at $35 \mathrm{X}$ and dichotomous keys (Triplehorn 2005; Marshall 2007; Marshall 2012).

\section{Parasitism of fifth instars}

To evaluate the occurrence of parasitism by tachinid flies, parasitoid wasps, and the protozoan parasite, Ophryocystis elektroscirrha $(\mathrm{OE})$, fifth instars from monitored patches were collected and reared until eclosion $(n=106$ total; 2015: $n=45 ; 2016: n=61)$. OE can be spread by vertical transmission from female to offspring with spores on the surface of the egg capsule or milkweed leaves being ingested by the emerging larvae (McLauglin and Myers 1970; Leong et al. 1997). Additionally, OE can spread by horizontal transmission between adults during mating or other interactions such as on flowers or roosting (Altizer and Oberhauser 1999). Spores must be ingested by the host to cause new infections (Leong et al. 1997). To minimize the transfer of spores between larvae, we followed the sampling procedure outlined by Project Monarch Health (University of Georgia; http://monarchparasites.org). Each larva was kept in an individual plastic container with mesh fabric held in place with rubber bands as a lid. Enclosures were cleaned daily by removing frass and old milkweed leaves. The containers were cleaned using a $20 \%$ 
chlorine bleach-water solution. Larvae were given fresh milkweed daily with a moist paper towel placed on the bottom of the enclosure to reduce dehydration of leaves. Milkweed leaves were obtained from non-monitored milkweed patches and soaked in $10 \%$ chlorine bleach-water solution for 20 min followed by rinsing and soaking for another 20 minutes in water prior to being given to larvae to kill OE spores that may have been on the leaves.

Eclosed adults were tested for OE ten hours or more after emergence. Following previous studies (Altizer et al. 2000; Satterfield et al. 2015; Altizer et al. 2015), OE spores were collected using a clear mailing sticker (2.54 cm diameter) wrapped around the sides of the abdomen and removed and then placed on a white index card. Spores were viewed and counted using a microscope at $65 \mathrm{X}$. Samples were assigned to parasite load classes according to the following ordinal scale: 0: no spores, 1: one spore, 2: 2-20 spores, 3: 21-100, 4: 101-1000 spores, 5: > 1000 spores (Altizer et al. 2000). Following previous studies (Altizer et al. 2000; Bartel et al. 2011; Satterfield et al. 2015; Altizer et al. 2015), these 6 parasite load classifications were then further generalized to a binary scale, with 0-3 = 'moderate to no infection', and 4-5 = 'heavily infected'.

Chrysalises that appeared abnormal and deceased were kept for an additional $7 \mathrm{~d}$ past typical emergence date to check for presence of emerging parasitoids. Larvae that did not eclose properly or died prior to eclosure were frozen and any emerged parasitoids were put into glass vials containing $75 \%$ ethanol.

\section{Statistical analyses}

To understand the factors that drive monarch butterfly oviposition preference, a generalized mixed-effects Poisson model was fitted using maximum likelihood (Laplace approximation) through the 'glmer' function in the package lme4 (Bates et al. 2015) in R v. 3.3-1 (R Development Core Team 2017). Because the response variable, egg count, was dependent upon 
the number of milkweed monitored, an offset of the number of milkweed monitored in the patch was included in the model such that fixed-effects parameter estimates were scaled on a per milkweed basis. Julian date, year (2015, 2016), landscape type (agriculture, non-agricultural, roadside), patch size (small, medium, large), and milkweed density were all included as fixedeffects. We included patch ID as a random effect because patches were checked each week over the breeding season. A two-way interaction between landscape type and patch size was also included to account for the possibility that the effect of patch size on the number of eggs per milkweed differed by landscape type. Significance of fixed effects was assessed using type III ANOVA with Wald chi-square tests (Bolker et al. 2009). The model evaluation approach used for all models was a backwards model selection based on a priori hypotheses to select the best fitting model using Akaike Information Criterion (AIC) values (Burnham and Anderson, 2002). Parameter estimates from the top model were used to predict the egg density across landscape type, patch size, and milkweed density to inform land managers of the most effective planting strategy depending on the site location and milkweed distribution.

To assess the effect of abundance and diversity of invertebrate predators and parasitoids on monarch oviposition, we performed four separate generalized mixed-effects Poisson models fitted using maximum likelihood (Laplace approximation) through the 'glmer' function in the package lme4 (Bates et al. 2015) in R v. 3.3-1 (R Development Core Team 2017). Firstly, a model was used to explain the abundance of invertebrate predators (the number of predators present per trap per sampling period), and a second model to explain the diversity of invertebrate predators (the number of individual families present per trap per sampling period). Additionally, a model was used to explain the abundance of parasitoids and a final model to predict the diversity of parasitoids. Julian date, year $(2015,2016)$, landscape type (agriculture, non- 
agricultural, roadside), patch size (small, medium, large), and milkweed density were all included as fixed-effects in all models. We included patch ID as a random effect because the same patches were sampled every other week over the breeding season. Significance of fixed effects was assessed using type II ANOVA with Wald chi-square tests (Bolker et al. 2009).

To understand the consequences of oviposition in regards to OE parasitism, a binomial generalized linear model (GLM) was used to predict the binary response variable, OE infection status (moderate to no infection/heavily infected) of collected fifth instars. Julian date, year $(2015,2016)$, landscape type (agriculture, non-agricultural, roadside), patch size (small, medium, large), and milkweed density were all included as fixed-effects.

\section{RESULTS}

\section{Egg density}

A total of 30,069 milkweeds were counted and checked for monarch eggs over two years (2015: $\mathrm{n}=6,526 ; 2016: \mathrm{n}=23,543)$. Monitored milkweed patches were distributed between landscape types with agricultural landscape having the most 'small' patches $\left(<16 \mathrm{~m}^{2}\right)$ and the fewest 'large' patches $\left(>28 \mathrm{~m}^{2}\right)$, while the opposite was found in roadside landscape (Table 1). Milkweed density in a patch was $2.7 \pm 5.3 \mathrm{milkweed} / \mathrm{m}^{2}($ mean $\pm \mathrm{SD})($ range $=0.1-58.0$ milkweeds $/ \mathrm{m}^{2}$ ) across all landscapes with agricultural landscape having the highest average milkweed density $\left(3.6 \pm 7.3\right.$ milkweed $\left./ \mathrm{m}^{2} ; \chi^{2}=6540, \mathrm{df}=2, \mathrm{p}=<0.0001\right)$ (Fig. 2)

From the monitored milkweed patches, a total of 1,988 eggs were counted over two years (2015: $n=1,071 ; 2016: n=917)$. Although eggs were laid in all landscape types, there were no eggs counted in 21 patches $(19 \%)(2015: \mathrm{n}=5 ; 2016: \mathrm{n}=16)$. Egg density, the number of eggs per milkweed in a given patch, was $0.1 \pm 0.4(\max .=4)$ across all landscapes (Fig. A-1). 
The best supported generalized mixed-effects Poisson model for egg density was the global model that included Julian date, year, landscape type, milkweed density, patch size, and the interaction between landscape type and patch size (Table A-1). All fixed effects were significant predictors of egg density (Table 2). Egg density tended to increase over the breeding season and was higher in 2015 compared to 2016. Agricultural landscape milkweed patches had significantly higher egg densities compared to roadside landscape patches. However, milkweed patches in non-agricultural landscape did not differ significantly from agricultural landscape in predicting egg density. Small milkweed patches $\left(<16 \mathrm{~m}^{2}\right)$ had higher egg density than medium patches $\left(16-28 \mathrm{~m}^{2}\right)$ and large patches $\left(>28 \mathrm{~m}^{2}\right)$. As expected, egg density decreased as milkweed density increased (Fig.3). In this model, there was also a significant negative interaction between landscape type and patch size suggesting that the effect of patch size on egg density differed by landscape type (Fig.3). In agricultural landscapes, small patches had the highest egg density followed by medium patches and lastly large patches (Fig.3). In non-agricultural landscapes, medium patches tended to have fewer eggs per milkweed than small and large patches (Fig. 3). In contrast, in roadside landscape, more eggs were laid per milkweed in medium patches than small patches, with fewest eggs laid in large patches (Fig. 3).

\section{Invertebrate predator abundance and diversity}

From the 86 patches monitored $(2015: \mathrm{n}=18 ; 2016: \mathrm{n}=68), 3,167$ invertebrate predators were identified and counted (Table 3). The abundance of invertebrate predators (count of predators per trap of predators per sampling period) was $12.9 \pm 26.1$ across all landscapes. Collectively, 15 different invertebrate predator families were sampled (max. per sample $=5$ ) and the diversity of invertebrate predators was $1.9 \pm 1.1$ across all landscapes types (Table 4).

The best model predicting invertebrate predator abundance included Julian date, year, 
and patch size but not landscape type (Table A-2). Predator abundance tended to decreased over the breeding period (Table 5) and medium milkweed patches $\left(16-28 \mathrm{~m}^{2}\right)$ tended to have higher predator abundance compared to small $\left(<16 \mathrm{~m}^{2}\right)$ and large patches $\left(>28 \mathrm{~m}^{2}\right)$ (Fig. 4). Although year was in the top model, it was not a significant predictor of invertebrate abundance.

There was not a clear top model for predator diversity (Table A-3). All models tested were within $6 \mathrm{AIC}$ of the best-fitting model. We conducted full model averaging on the three top models $(\triangle \mathrm{AIC}<2)$. Predator diversity decreased over the breeding season $(\beta \pm \mathrm{SE}:-0.0084 \pm$ $0.0039, Z=-2.17,95 \%$ CI: $[-0.016,-0.00095])$. However, the $95 \%$ confidence interval of year $(\beta$ $\pm \mathrm{SE}:-0.055 \pm 0.13, Z=0.43,95 \% \mathrm{CI}:[-0.19,0.31]$ ), landscape type (nonagricultural $\beta \pm \mathrm{SE}:-$ $0.038 \pm 0.11, Z=0.34,95 \%$ CI: $[-0.18,0.26]$; roadside $\beta \pm \mathrm{SE}:-0.15 \pm 0.12, Z=-1.26,95 \% \mathrm{CI}$ : $[-0.38,0.081])$, milkweed density $(\beta \pm$ SE: $-0.00024 \pm 0.013, Z=-0.019,95 \%$ CI: $[-0.025,-$ 0.025]), and patch size (small $\beta \pm$ SE: $0.16 \pm 0.12, Z=1.32,95 \%$ CI: [-0.0075, 0.42]; medium $\beta$ $\pm \mathrm{SE}: 0.15 \pm 0.15, Z=0.97,95 \% \mathrm{CI}:[-0.15,0.46])$ overlapped with zero (Fig. 5).

\section{Parasitoid abundance and diversity}

The same 86 monitored patches $(2015: \mathrm{n}=18 ; 2016: \mathrm{n}=68)$ were used to sample parasitoid abundance and diversity (Table 3). From the collected samples, 704 parasitoids were identified and counted (Table 4). The abundance of parasitoids (count of parasitoids per trap per sampling period) was $2.9 \pm 5.2$ across all landscapes. Collectively, four different parasitoid families were present in the samples (max. per sample $=2$ ). The diversity of parasitoids was $0.96 \pm 0.60$ per trap across all landscape types.

The best model to explain parasitoid abundance included year and landscape type, and excluded milkweed density and patch size (Table A-4). Year and landscape type were significant predictors of parasitoid abundance. Parasitoid abundance was greater in 2015 than 2016, and 
roadside landscapes had a lower abundance of parasitoids compared to agricultural and nonagricultural landscapes (Table 6; Fig. 6).

There was not a clear top model for parasitoid diversity (Table A-5). All models tested were within 6 AIC of the best-fitting model. We conducted full model averaging on the three top models $(\triangle \mathrm{AIC}<2)$. However, the $95 \%$ confidence interval of Julian date $(\beta \pm \mathrm{SE}:-0.0059 \pm$ $0.0056, Z=1.07,95 \%$ CI: $[-0.0048,0.017])$, year $(\beta \pm$ SE: $-0.056 \pm 0.16, Z=-0.35,95 \%$ CI: [$0.36,0.27]$ ), landscape type (non-agricultural $\beta \pm \mathrm{SE}:-0.040 \pm 0.16, Z=-0.24,95 \% \mathrm{CI}:[-0.36$, $0.28]$; roadside $\beta \pm \mathrm{SE}:-0.28 \pm 0.18, Z=-1.58,95 \% \mathrm{CI}:[-0.63,0.063]$ ), patch size (small $\beta \pm$ SE: $0.060 \pm 0.19, Z=0.32,95 \% \mathrm{CI}:[-0.30,0.44]$; medium $\beta \pm \mathrm{SE}: 0.17 \pm 0.22, Z=0.76,95 \%$

CI: $[-0.26,0.60])$, and milkweed density $(\beta \pm \mathrm{SE}: 0.016 \pm 0.013, Z=1.26,95 \% \mathrm{CI}:[-0.013$, 0.037]) overlapped with zero (Fig. 7).

\section{Parasitism by Ophryocystis elektroscirrha}

From the 106 fifth instars collected, $18(2015: \mathrm{n}=11 ; 2016: \mathrm{n}=7)$ were heavily infected $(>100$ spores) with the protozoan parasite, OE (Table 7). Two of the collected fifth instars were parasitized by tachinid flies and, therefore, were not able to be tested for OE parasitism. The highest infection rate was found in roadside landscapes (Table 7). The best fitting binomial generalized linear model, based on AIC comparisons, included Julian date, year, landscape type, and milkweed density as predictors of OE (Table A-6). However, the confidence interval of Julian date $(\beta \pm$ SE: $-0.0047 \pm 0.024, Z=0.20,95 \%$ CI: $[-0.040,0.054])$, year $(\beta \pm$ SE: $--0.53 \pm$ $0.56, Z=-0.97,95 \% \mathrm{CI}:[-1.65,0.57])$, landscape type (non-agricultural $\beta \pm \mathrm{SE}:-0.96 \pm 1.17, Z$ $=-0.83,95 \%$ CI: $[-4.00,1.02]$; roadside $\beta \pm \mathrm{SE}: 0.82 \pm 0.66, Z=1.26,95 \%$ CI: $[-0.49,2.12])$, 
and milkweed density ( $\beta \pm$ SE: $-0.26 \pm 0.19, Z=-1.39,95 \% \mathrm{CI}:[-0.74,0.024])$ overlapped with zero.

\section{DISCUSSION}

Our study is the first to examine monarch butterfly preference and consequences of oviposition on multiple spatial scales, which has important implications for restoration and management decisions related to this declining species. We provide evidence that monarch butterfly oviposition patterns are related to both the size and density of the milkweed patch, as well as the landscape in which the milkweed patches reside. Small $\left(<16 \mathrm{~m}^{2}\right)$ and low-density $(0-2$ milkweed stems per $\mathrm{m}^{2}$ ) milkweed patches in agricultural landscapes had the highest egg density compared to larger milkweed patches and higher milkweed densities found in non-agricultural and roadside landscapes. Consistent with previous literature (Zalucki and Kitching 1982a; Zalucki 1987; Pleasants and Oberhauser 2013; Stenoien et al. 2016), we also found that low-density milkweed patches had greater egg density across all landscape types and patch sizes than high-density milkweed patches. In two of the three landscape types (agriculture and non-agriculture), we found that predator abundance was highest in patch sizes where egg density was lowest. In contrast, we found no support for predator diversity or parasitoid abundance/diversity driving egg-laying patterns by patch size. Furthermore, we did not find evidence that rates of OE parasitism varied by landscape type, milkweed density, or patch size.

Our results have important implications for restoration of milkweeds for conserving monarch populations. Given the option, agricultural fields appear to be the most effective landscape to plant and maintain milkweeds to attract egg-laying females. Milkweed stems in agricultural landscape sampled in our Ontario-based study averaged 3.5 times more monarch 
eggs than milkweed stems in non-agricultural landscape, comparable but slightly lower than that found by Pleasants and Oberhauser (2013) in Midwest US. One important implication, therefore, is that it will be vital to develop incentive programs working with landowners to plant and maintain milkweeds in agricultural landscapes. Programs for milkweed restoration could be in conducted in collaboration with other pollinator initiatives or ecosystem service programs in agricultural landscapes that focus on increasing nectar availability (e.g. Alternative Land Use Service, ALUS; Conservation Reserve Program, CRP). Ideal areas for planting milkweed patches could be in crop margins, field corners, or other marginalized land within close proximity to crop fields. Consideration should be made for areas where milkweed will not be trampled by machinery or livestock or sprayed by herbicides during the breeding season.

If milkweed restoration in agricultural landscapes is difficult to implement or not feasible, our results suggest that non-agricultural landscapes may be the next most effective landscape for attracting egg-laying females rather than roadsides. Non-agricultural milkweed patches are commonly large as they are left to naturalize and are not subject to pesticides or vegetation management. Large milkweed patches may be particularly important to consider for restoration because they tend to house a higher density of male monarchs searching for mates. Previous work has provided evidence of a male-biased sex ratio around large, high-density milkweed patches, while showing that females tend to reside outside of these patches (Zalucki and Kitching 1984; Bull et al. 1985). Small milkweed patches in non-agricultural landscapes, such as in gardens and urban parks, while not as preferred as agricultural patches can still provide usable egg-laying habitat and are usually in close proximity to other nectar sources that can provide energy for adults. Restoration efforts in urban areas include registering and certifying monarch waystations (Monarch Watch, University of Kansas, 
www.monarchwatch.org), to encourage creating habitat that includes milkweeds and nectar sources to support monarchs both during the breeding season and migration. Additionally, the new 'Butterflyway Project', organized by the David Suzuki Foundation (www.butterflyway.davidsuzuki.org), works on creating a network of wildflower patches across large urban cities in Canada.

Despite the fact that roadside habitat is abundant throughout North America, milkweed patches in this landscape received half the amount of eggs of what was laid in agricultural landscape patches. One possible reason for this could be that females are often not reaching roadside milkweed because of high mortality from vehicle collisions (Munguira and Thomas 1992; McKenna et al. 2001; Ries et al. 2001). Roadside habitats can also be detrimental for developing larvae in the form of heavy metal contamination from cars that can leech into the soil and vegetation (Lagerweff and Specht 1970; Scanlon 1987), mowing milkweed that contain eggs and larvae, and road salt runoff (Snell-Rood et al. 2014). Road salt runoff can affect neural investment that result in larger eyes in female monarchs and increased muscle mass in male monarchs (Snell-Rood et al. 2014). Monarchs reared on roadside-collected milkweed leaves also had lower survival than monarchs reared on prairie-collected milkweed leaves (Snell-Rood et al. 2014). Thus, even if some roadsides are appealing to females for oviposition due to availability of host plants, nectar sources, and sodium, they could result in decreased survival of larvae. In this sense, it is possible that some roadsides could act as ecological traps (Dwernychuk and Boag 1972; Ries et al. 2001; Battin 2004). We have noted multiple factors that affect monarch persistence in roadside habitats, however it is not well understood from an evolutionary perspective how these effects may drive natural selection and the resulting consequences on the 
population (Brady and Richardson 2017). These factors, combined with our results, suggest that investing heavily in milkweed restoration in roadside habitats should be met with some caution.

While the overall differences in oviposition preference between landscape types are consistent with previous literature reporting that monarchs lay more eggs in agricultural areas (Oberhauser et al. 2001; Pleasants and Oberhauser 2013), it is still unclear as to why agricultural landscapes are more attractive for oviposition compared to other landscapes. One explanation for why agricultural landscapes are attractive could be the use of fertilizer, which would run off into areas along field margins where milkweeds are growing. Host plants with higher nitrogen levels have been shown to increase development in some species of Lepidoptera (Slansky and Feeny 1977; Tabashnik 1982; Taylor 1984), and increase larval survival (Myers and Post 1981; Myers 1985; Clancy 1992). There is some equivocal evidence that plant nitrogen content could also influence oviposition preference in other species of Lepidoptera. Cabbage white butterflies (Pieris rapae) prefer to oviposit on plants that have higher nitrogen content (Myers 1985). In contrast, neither copper butterflies (Lycaena tityrus; Fischer and Fiedler 2000) nor monarchs in Australia (Oyeyele and Zalucki 1990) showed oviposition preference for plants with higher nitrogen.

Another proximate factor driving oviposition preference in agricultural landscapes could be that the chemical signals used to locate milkweeds are easier for females to distinguish in monoculture fields versus milkweed that are embedded in more complex plant communities (Pleasants and Oberhauser 2013). Using chemical receptors on antenna (Thorsteinson 1960), insects recognize host plants by comparing ratios of host plant volatiles against the volatiles of surrounding plants (Bruce et al. 2005). Thus, detection of a host plant is thought to be more difficult when surrounded by a high diversity of other plants (Tahvanainen and Root 1972; Finch 
and Collier 2000). However, if the surrounding plants are all one species, as in a monoculture crop field, this could make a milkweed's chemical signal easier to detect by females seeking to lay eggs.

While monarch egg density was higher in agricultural landscapes, our results also suggest that the effect of patch size on egg density varied across different landscape types. In both agricultural and non-agricultural landscapes, medium milkweed patches contained lower egg density than small or large patches. A mechanism that we did not test that could explain this pattern is male avoidance. The number of males in a habitat has been shown to be negatively related to the number of eggs per plant in Australia (Zalucki and Suzuki 1987). Males tend to frequent larger milkweed patches (Zalucki and Kitching 1984; Bull et al. 1985). However, females are frequently harassed by males; they experience forced copulations from mature males (Oberhauser and Frey 1999) as well as highly aggressive behaviour from juvenile males (Zalucki and Suzuki 1987). Once a female has mated, she avoids other males and searches for egg laying locations.

In contrast to agricultural and non-agricultural landscapes, egg density in roadside landscapes was highest in medium-sized milkweed patches. One explanation for this surprising result could be that small roadside patches are mowed more frequently than larger roadside patches, which could result in failing to locate eggs if the patch was mowed in between visits. Small patches could have also be harder to locate in roadside landscape, as vegetation is restricted between the edges of the roads and property borders causing vegetation to grow in closer proximity to other plants. Alternatively, females may avoid small patches in roadside landscapes if they contain more predators. Although not significant, we found a higher abundance of predators in small roadside patches than in medium and large roadside patches. 
Despite the fact that monarchs lay more eggs in low-density milkweed patches, our results suggest that this cannot be explained by a lower abundance of predators, parasitoids, or parasites in this type of habitat. An alternative explanation could be that females are attracted to low-density milkweed patches because the quality of milkweed in these patches is higher than in high-density patches. Plants growing in high-density would likely experience increased competition for resources compared to plants growing in a low-density spatial arrangement. Plant nutrient uptake is proportional to the root length density (Reich et al. 2003; Raynaud and Leadley 2004; Craine et al. 2005), which could be restricted and reduced when growing more closely to surrounding stems. Milkweed stems of higher nutrient quality due to from growing in a lower competitive environment could be preferred by females, to provide larvae with higher quality host plants.

Although egg density was highest in agricultural milkweed patches, our results suggest this cannot be attributed to a lower abundance of invertebrate predators in agricultural landscape. In contrast to our lack of support of invertebrate predator abundance being lower in agricultural landscape, $74 \%$ of studies reviewed by Bianchi et al. (2006) showed that populations of predatory invertebrates were higher in complex, non-crop habitats compared to simplified agricultural landscapes. In the present study, we did not quantify the abundance or diversity of surrounding vegetation. However, while the abundance of predators did not differ between landscape types, it was influenced by the size of the milkweed patch and Julian date. We found that medium patches had the highest predator abundance compared to small and large patches, coinciding with medium patches having the lowest monarch egg density in both agricultural and non-agricultural landscapes.

While predator abundance was not influenced by landscape type, parasitoids were least 
abundant in roadside milkweed patches in roadside milkweed patches where females laid the fewest eggs compared to agricultural and non-agricultural landscapes. An overall lower abundance of insects in roadside landscapes could be due to reduced vegetation in the landscape (Murdoch et al. 1972; Southwood et al. 1979; Lawton 1983), therefore limiting available hosts for parasitoids. Roadsides in our study area mostly consisted of planted non-native grasses (Poa pratensis) as well as common roadside flowering species (e.g. Trifolium repens, Lotus corniculatus, Cichorium intybus), many of which are invasive and may not support native insect species. Adult parasitoids not only need to find hosts but must also find food sources to meet their nutritional needs. Adult tachinid flies feed on a variety of substrates including flower nectar (Gilbert and Jervis 1999), hemipteran honeydew (Zoebelein 1956) and host/non-host tissue (Jervis et al. 1992). Some adult parasitoid wasps can feed on similar substrates including nectar (Lewis et al. 1998), pollen (Patt et al. 1997), and honeydew (Lee et al. 2004; Wäckers and Steppuhn 2003). Parasitoids also require a host or location for overwintering. Tachinid flies generally overwinter as larvae within the pupae of their host (Schaffner and Griswold 1934; O’Hara 1999), which would not be possible in monarchs because adults migrate south. Alternatively, tachinid flies could overwinter in a different host, soil, or leaf litter (Oberhauser et al. 2007). Parasitoid wasp larvae typically rely less on their host to overwinter as they build cocoons which fall into the soil where they pupate and eclose the following spring (Fulton 1940). We expected agricultural landscapes to have higher monarch egg density in part due to fewer parasitoids. Therefore, we would expect agricultural landscape to also not be able to support parasitoid populations because of their low plant diversity. One discrepancy between the landscapes types is frequent mowing of vegetation and spraying for invasive species in roadside landscapes. 
There was no support that $\mathrm{OE}$ rates differed by landscape type, patch size, or milkweed density in a patch, which could be due to the overall low abundance of OE in this region and resultant low statistical power. Testing for differences in OE parasitism between habitats was limited by the number of fifth instars detected. The overall prevalence of $\mathrm{OE}$ is low in the eastern North American population and, therefore, requires a large sample size to be able to make inferences about differences between landscape types or habitats (Bradley and Altizer 2005). It is possible that the OE prevalence in the northern range of the eastern North American monarch population is so low that $\mathrm{OE}$ may not be a factor that influences egg laying in that region, but it could still be a contributing factor to oviposition preference in more southern locations.

It is important to note that conclusions drawn about the effect of patch size on egg density should be made with some caution because of the uneven distribution of patch sizes that were sampled across the landscape types. Differences in the distribution of patch sizes across landscapes was likely due to differences in vegetation structure and management practices. In non-agricultural (e.g. meadows and fields) and roadside landscapes, milkweed is commonly not managed and left to naturalize with patches growing larger over time, rendering small milkweed patches relatively uncommon in these landscapes. Conversely, large milkweed patches are rare in agricultural landscapes, which is likely due to both the use of herbicides and the widening of crop fields, which reduces field margins where milkweed commonly grows. There were also different distributions of milkweed patch density between landscape types. Non-agricultural patches tended to have lower milkweed density than agricultural and roadside patches. The difference in densities could be due to non-agricultural landscapes commonly having a greater availability of land and providing more space for milkweeds to grow compared to agricultural and roadside habitats which are often restricted by property borders and crops. While one 
obvious solution to uneven distribution of patch sizes and densities between different landscape types would be to plant specific sized patches and densities, this would be challenging to execute. Creating patches of milkweed plants would include growing plants and transplanting plants and waiting for multiple growing seasons for the patches to become established with a mixture of mature and young plants. Female's oviposition preference may be affected by the age of the plant, but it also important to have mature plants to secure the establishment of the patch in future growing seasons. Furthermore, establishing large (e.g. $>28 \mathrm{~m}^{2}$ ) milkweed patches in agricultural landscapes might be difficult due to space restrictions.

While we have provided evidence that egg-laying preferences in monarchs are influenced by patch size, milkweed density, and landscape type, we acknowledge that there may be additional factors affecting female choice of sites. One of these factors could be the proximity of milkweed patches to each other on the landscape. Using a simulated egg-laying model, Zalucki and Lammers (2010) showed that when small milkweed patches are removed from the matrix (the area between larger patches), search time for milkweeds increased, resulting in reduced lifetime potential fecundity by $\sim 20 \%$. However, there are no empirical data to support this hypothesis. A second factor to consider could be the quality of the milkweed plants, such as height, age, and leaf quality. Females have been shown to prefer young plants that have newly emerged leaves (Zalucki and Kitching 1982a), and taller plants that are closer to flowering with intermediate levels of cardenolides (Cohen and Brower 1982; Malcolm and Brower 1986; Oyeyele and Zalucki 1990) in a variety of milkweed species. However, the mechanism behind these preferences for oviposition is not well understood. Bergström et al. (1995) compared plant volatiles from new and old leaves in two milkweed species (A. syriaca, A. curassavica) and there was no volatile unique to either leaf age class. 
Although we have provided evidence for factors that influence the preference of egglaying sites, a key question remains: do these same characteristics influence the subsequent survival of larva? It is possible that even though oviposition preference is higher in small agricultural patches, survival could be relatively low due to the use of agro-chemicals and predators. From our results the abundance of predators in agricultural landscapes was comparable to that of non-agricultural and roadside landscapes, suggesting that agricultural patches do not act as a prey refuge for monarchs. Monarchs are susceptible to many predators and have a very high mortality rate, $\sim 88-98 \%$ during egg and early larval instars (Borkin 1982; Zalucki and Kitching 1982b; Prysby 2004; Nail et al. 2015), therefore having a significant impact on population growth. How agrochemicals, such as neonicotinoids, affect larval survival is not well understood. Neonicotinioid insecticides (e.g. clothianidin) are the most widely used class of insecticide (Goulson 2013). These compounds are water-soluble (Tomizawa and Casida 2005), allowing for uptake into plants (Krupke et al. 2012) including milkweeds (Pecenka and Lundgren 2015). Some research has suggested that monarch larvae on milkweeds in agricultural fields may be exposed to neonicotinoids (Pecenka and Lundgren 2015). It is unknown what sublethal effects neonicotinoid exposure might have on monarch behaviour during foraging and navigation. It is crucially important to understand the factors that affect larval survival in relation to habitat in order to aid in monarch population recovery.

Our study examined monarch egg-laying preferences in Ontario but it is possible that these results are not generalizable to the entire eastern North American monarch population. There are over 100 species of milkweeds in North America, with monarchs using 27 species in the genus Asclepias, and a few related genera, Cynanchum and Sarcostemma as host plants (Malcolm and Brower 1986). In our study area Ascelpias syriaca, A. incarnata, and A. tuberosa 
are the three milkweed species. It is possible that oviposition preference could differ depending on the milkweed species available. Additionally, because our study area is on the northern edge of the eastern North American monarch population range, fewer monarchs reach this far north during the spring and summer migration. With a higher density of monarchs further south, female preference for oviposition sites may not be as apparent simply because of higher competition for egg laying sites.

In summary, we found that monarch egg density was highest in small, low-density milkweed patches in agricultural landscape. Small milkweed patches also yielded lower invertebrate predator abundance than medium patches. Based on these findings it will be important to develop programs with landowners and other pollinator initiatives or ecosystem service programs to actively restore milkweed in agricultural landscapes. Ideal areas for planting milkweed patches are crop margins, field corners, and other marginalized land within close proximity to crop fields. Small and large patches in non-agricultural landscapes provide the next most effective landscape for attracting egg-laying females. Large patches may also be important for providing a location for male monarchs to searching for mates. Roadside patches which received half the amount of eggs compared to agricultural landscapes, may potentially pose a number of threats to monarchs; restoration should, therefore, be approached with some caution. Detailed planning and immediate action is needed to continue to help protect this vulnerable and rapidly declining species. 
Table 1. Number of monitored milkweed patches in each size category, by landscape type over 6-week periods in both 2015 and 2016.

\begin{tabular}{lccc}
\hline & \multicolumn{3}{c}{ Milkweed patch size categories } \\
\cline { 2 - 4 } Landscape & $\begin{array}{c}\text { Small } \\
\left(<16 \mathrm{~m}^{2}\right)\end{array}$ & $\begin{array}{c}\text { Medium } \\
\left(16-28 \mathrm{~m}^{2}\right)\end{array}$ & $\begin{array}{c}\text { Large } \\
\text { Agricultural }\end{array}$ \\
Non-agricultural & 276 & 42 & 12 \\
Roadside & 99 & 27 & 36 \\
Total & 65 & 39 & 65 \\
\hline
\end{tabular}


Table 2. Parameter estimates from the top mixed effects generalized linear model (based on AIC model selection, see Table A-1) to explain egg density based on landscape type, Julian date, year, patch size, milkweed density, and patch ID. Note the intercept value represents the predicted egg density in large agricultural patches. We report 95\% confidence intervals. ‘ * represents parameters that do not overlap with zero.

\begin{tabular}{|c|c|c|c|c|}
\hline Parameter & Estimate \pm SE & z & $\begin{array}{c}5 \% \text { Confidence } \\
\text { Interval }\end{array}$ & SD \\
\hline \multicolumn{5}{|l|}{ Random effect } \\
\hline Patch ID & & & & 0.85 \\
\hline \multicolumn{5}{|l|}{ Fixed effects } \\
\hline Intercept * & $-2.51 \pm 0.60$ & -4.16 & $-3.73,-1.30$ & \\
\hline Julian Date * & $0.22 \pm 0.025$ & 8.68 & $0.17,0.26$ & \\
\hline Year 2016 * & $-0.58 \pm 0.12$ & -5.46 & $-0.80,-0.37$ & \\
\hline Non-agricultural & $-0.13 \pm 0.70$ & -0.19 & $-1.55,1.25$ & \\
\hline Roadside * & $-1.70 \pm 0.66$ & -2.59 & $-3.05,-0.39$ & \\
\hline Small Patch & $0.50 \pm 0.62$ & 0.81 & $-0.80,1.74$ & \\
\hline Medium Patch * & $-1.71 \pm 0.68$ & -2.51 & $-3.14,-0.39$ & \\
\hline Milkweed Density * & $-0.30 \pm 0.09$ & -3.35 & $-0.48,-0.13$ & \\
\hline Non-agricultural: Small Patch & $-0.51 \pm 0.74$ & -0.69 & $-2.00,0.99$ & \\
\hline Roadside: Small Patch & $0.30 \pm 0.74$ & 0.40 & $-1.17,1.84$ & \\
\hline Non-agricultural: Medium Patch & $-0.012 \pm 0.92$ & -0.013 & $-1.84,1.88$ & \\
\hline Roadside: Medium Patch * & $3.18 \pm 0.77$ & 4.13 & $1.41,4.79$ & \\
\hline
\end{tabular}


Table 3. Summary of the number of samples collected for invertebrate predator and parasitoid abundance and diversity sampling for each milkweed patch size and landscape type. Sampling was conducted every other week with a given patch being sampled a maximum of 3 times over the total 6-week period.

\begin{tabular}{lccc}
\hline & \multicolumn{3}{c}{ Milkweed patch sizes } \\
\cline { 2 - 4 } & Small & Medium & Large \\
Landscape & $\left(<16 \mathrm{~m}^{2}\right)$ & $\left(16-28 \mathrm{~m}^{2}\right)$ & $\left(29-472 \mathrm{~m}^{2}\right)$ \\
\hline Agricultural & 72 & 16 & 6 \\
Non-agricultural & 50 & 13 & 26 \\
Roadside & 29 & 16 & 49 \\
Total & 151 & 45 & 26 \\
\hline
\end{tabular}


Table 4. Mean and total number (in brackets) of individual invertebrate predators and parasitoids by family per pan trap sample. * represents families that included both adults and larval stages.

\begin{tabular}{|c|c|c|c|c|c|c|c|c|c|}
\hline \multirow{2}{*}{$\begin{array}{l}\text { Invertebrate } \\
\text { Predators }\end{array}$} & \multicolumn{3}{|c|}{ Agriculture } & \multicolumn{3}{|c|}{ Non-agriculture } & \multicolumn{3}{|c|}{ Roadside } \\
\hline & Small & Med. & Large & Small & Med. & Large & Small & Med. & Large \\
\hline Formicidae & $\begin{array}{c}6 \\
(569)\end{array}$ & $\begin{array}{l}4.3 \\
(55)\end{array}$ & $\begin{array}{l}6.7 \\
(40)\end{array}$ & $\begin{array}{c}13 \\
(494)\end{array}$ & $\begin{array}{l}27.5 \\
(579)\end{array}$ & $\begin{array}{c}6.9 \\
(125)\end{array}$ & $\begin{array}{l}13.8 \\
(245)\end{array}$ & $\begin{array}{c}7.8 \\
(140)\end{array}$ & $\begin{array}{c}5.0 \\
(168)\end{array}$ \\
\hline Vespidae & $\begin{array}{c}0 \\
0\end{array}$ & $\begin{array}{c}0 \\
(0)\end{array}$ & $\begin{array}{c}0 \\
(0)\end{array}$ & $\begin{array}{l}0.3 \\
(1)\end{array}$ & $\begin{array}{c}0 \\
(0)\end{array}$ & $\begin{array}{c}0.06 \\
(1)\end{array}$ & $\begin{array}{l}0.3 \\
(3)\end{array}$ & $\begin{array}{l}0.4 \\
(4)\end{array}$ & $\begin{array}{c}0 \\
0\end{array}$ \\
\hline Carabidae & $\begin{array}{l}1.3 \\
(59)\end{array}$ & $\begin{array}{l}1.1 \\
(23)\end{array}$ & $\begin{array}{c}1.7 \\
(10)\end{array}$ & $\begin{array}{l}0.7 \\
(26)\end{array}$ & $\begin{array}{l}1.8 \\
(42)\end{array}$ & $\begin{array}{l}0.5 \\
(9)\end{array}$ & $\begin{array}{l}0.3 \\
(8)\end{array}$ & $\begin{array}{l}0.4 \\
(7)\end{array}$ & $\begin{array}{c}0.6 \\
(12)\end{array}$ \\
\hline Cicindelidae & $\begin{array}{c}0.07 \\
(4)\end{array}$ & $\begin{array}{l}0.1 \\
(3)\end{array}$ & $\begin{array}{l}0.7 \\
(2)\end{array}$ & $\begin{array}{l}0.1 \\
(4)\end{array}$ & $\begin{array}{l}0.4 \\
(9)\end{array}$ & $\begin{array}{c}1 \\
(18)\end{array}$ & $\begin{array}{c}0 \\
(0)\end{array}$ & $\begin{array}{c}0 \\
(0)\end{array}$ & $\begin{array}{c}0.05 \\
(1)\end{array}$ \\
\hline Coccinellides* & $\begin{array}{c}0.2 \\
(12)\end{array}$ & $\begin{array}{c}0 \\
(0)\end{array}$ & $\begin{array}{c}0 \\
0 \\
(0)\end{array}$ & $\begin{array}{c}0 \\
0 \\
(0)\end{array}$ & $\begin{array}{c}0 \\
(0)\end{array}$ & $\begin{array}{c}0 \\
0\end{array}$ & $\begin{array}{c}0 \\
(0)\end{array}$ & $\begin{array}{c}0 \\
0 \\
(0)\end{array}$ & $\begin{array}{c}0 \\
0 \\
(0)\end{array}$ \\
\hline Anthocoridae & $\begin{array}{l}0.05 \\
(3)\end{array}$ & $\begin{array}{c}0.09 \\
(2)\end{array}$ & $\begin{array}{c}0 \\
(0)\end{array}$ & $\begin{array}{c}0.05 \\
(2)\end{array}$ & $\begin{array}{c}0.04 \\
(1)\end{array}$ & $\begin{array}{c}0 \\
(0)\end{array}$ & $\begin{array}{c}0 \\
(0)\end{array}$ & $\begin{array}{c}0 \\
(0)\end{array}$ & $\begin{array}{l}0.1 \\
(1)\end{array}$ \\
\hline Reduviidae & $\begin{array}{c}0.04 \\
(2)\end{array}$ & $\begin{array}{c}0 \\
(0)\end{array}$ & $\begin{array}{l}0.3 \\
(1)\end{array}$ & $\begin{array}{c}0.08 \\
(3)\end{array}$ & $\begin{array}{l}0.1 \\
(3)\end{array}$ & $\begin{array}{l}0.3 \\
(5)\end{array}$ & $\begin{array}{l}0.3 \\
(5)\end{array}$ & $\begin{array}{c}0 \\
0 \\
(0)\end{array}$ & $\begin{array}{l}0.2 \\
(3)\end{array}$ \\
\hline Nabidae & $\begin{array}{c}0.05 \\
(2)\end{array}$ & $\begin{array}{l}0.1 \\
(1)\end{array}$ & $\begin{array}{l}0.3 \\
(1)\end{array}$ & $\begin{array}{l}0.3 \\
(10)\end{array}$ & $\begin{array}{l}0.3 \\
(6)\end{array}$ & $\begin{array}{l}0.3 \\
(6)\end{array}$ & $\begin{array}{c}0 \\
(0)\end{array}$ & $\begin{array}{l}0.2 \\
(2)\end{array}$ & $\begin{array}{c}0.08 \\
(3)\end{array}$ \\
\hline Berytidae & $\begin{array}{c}0.02 \\
(1)\end{array}$ & $\begin{array}{c}0 \\
(0)\end{array}$ & $\begin{array}{c}0 \\
(0)\end{array}$ & $\begin{array}{c}0 \\
(0)\end{array}$ & $\begin{array}{c}0 \\
(0)\end{array}$ & $\begin{array}{c}0.06 \\
(1)\end{array}$ & $\begin{array}{l}0.1 \\
(1)\end{array}$ & $\begin{array}{c}0 \\
(0)\end{array}$ & $\begin{array}{c}0.05 \\
(1)\end{array}$ \\
\hline Phymatinae & $\begin{array}{c}0 \\
(0)\end{array}$ & $\begin{array}{c}0 \\
(0)\end{array}$ & $\begin{array}{c}0 \\
(0)\end{array}$ & $\begin{array}{c}0 \\
(0)\end{array}$ & $\begin{array}{c}0.04 \\
(1)\end{array}$ & $\begin{array}{c}0 \\
(0)\end{array}$ & $\begin{array}{c}0 \\
(0)\end{array}$ & $\begin{array}{c}0 \\
(0)\end{array}$ & $\begin{array}{c}0 \\
(0)\end{array}$ \\
\hline Asopinae* $^{*}$ & $\begin{array}{c}0 \\
(0)\end{array}$ & $\begin{array}{c}0 \\
(0)\end{array}$ & $\begin{array}{c}0 \\
(0)\end{array}$ & $\begin{array}{c}0 \\
(0)\end{array}$ & $\begin{array}{c}0 \\
(0)\end{array}$ & $\begin{array}{c}0 \\
(0)\end{array}$ & $\begin{array}{c}0 \\
(0)\end{array}$ & $\begin{array}{l}0.1 \\
(1)\end{array}$ & $\begin{array}{c}0 \\
(0)\end{array}$ \\
\hline Chrysopidae* & $\begin{array}{c}0 \\
(0)\end{array}$ & $\begin{array}{c}0 \\
(0)\end{array}$ & $\begin{array}{c}0 \\
(0)\end{array}$ & $\begin{array}{c}0.02 \\
(1)\end{array}$ & $\begin{array}{c}0 \\
(0)\end{array}$ & $\begin{array}{c}0 \\
(0)\end{array}$ & $\begin{array}{c}0 \\
(0)\end{array}$ & $\begin{array}{c}0 \\
(0)\end{array}$ & $\begin{array}{c}0 \\
(0)\end{array}$ \\
\hline Dermaptera & $\begin{array}{c}0 \\
(0)\end{array}$ & $\begin{array}{c}0 \\
(0)\end{array}$ & $\begin{array}{c}0 \\
(0)\end{array}$ & $\begin{array}{c}0.3 \\
(11)\end{array}$ & $\begin{array}{l}0.2 \\
(3)\end{array}$ & $\begin{array}{c}0 \\
(0)\end{array}$ & $\begin{array}{c}0.06 \\
(1)\end{array}$ & $\begin{array}{c}0 \\
(0)\end{array}$ & $\begin{array}{c}0 \\
(0)\end{array}$ \\
\hline Phalangidae & $\begin{array}{c}2.2 \\
(117)\end{array}$ & $\begin{array}{l}2.9 \\
(62)\end{array}$ & $\begin{array}{c}9.3 \\
(28)\end{array}$ & $\begin{array}{l}0.2 \\
(8)\end{array}$ & $\begin{array}{l}0.3 \\
(8)\end{array}$ & $\begin{array}{c}0.6 \\
(11)\end{array}$ & $\begin{array}{c}5.2 \\
(105)\end{array}$ & $\begin{array}{c}3.1 \\
(56)\end{array}$ & $\begin{array}{c}0.5 \\
(11)\end{array}$ \\
\hline Schedylidae & $\begin{array}{c}0.05 \\
(3)\end{array}$ & $\begin{array}{l}0.1 \\
(1)\end{array}$ & $\begin{array}{c}0 \\
(0)\end{array}$ & $\begin{array}{c}0 \\
(0)\end{array}$ & $\begin{array}{c}0 \\
(0)\end{array}$ & $\begin{array}{c}0 \\
(0)\end{array}$ & $\begin{array}{c}0 \\
(0)\end{array}$ & $\begin{array}{c}0 \\
(0)\end{array}$ & $\begin{array}{c}0 \\
(0)\end{array}$ \\
\hline Parasitoids & & & & & & & & & \\
\hline Tachinidae & $\begin{array}{c}0.2 \\
(20)\end{array}$ & $\begin{array}{l}0.1 \\
(3)\end{array}$ & $\begin{array}{l}0.7 \\
(4)\end{array}$ & $\begin{array}{c}0.5 \\
(20)\end{array}$ & $\begin{array}{l}0.3 \\
(6)\end{array}$ & $\begin{array}{l}0.5 \\
(9)\end{array}$ & $\begin{array}{c}0.15 \\
(4)\end{array}$ & $\begin{array}{c}0 \\
(0)\end{array}$ & $\begin{array}{l}0.3 \\
(5)\end{array}$ \\
\hline Pteromalidae & $\begin{array}{c}0.9 \\
(66)\end{array}$ & $\begin{array}{c}1.8 \\
(26)\end{array}$ & $\begin{array}{l}0.6 \\
(4)\end{array}$ & $\begin{array}{c}0.5 \\
(19)\end{array}$ & $\begin{array}{c}1.5 \\
(38)\end{array}$ & $\begin{array}{c}0.5 \\
(10)\end{array}$ & $\begin{array}{c}0.5 \\
(13)\end{array}$ & $\begin{array}{c}0.5 \\
(11)\end{array}$ & $\begin{array}{c}0.5 \\
(14)\end{array}$ \\
\hline Braconidae & $\begin{array}{c}0.6 \\
(44)\end{array}$ & $\begin{array}{c}0.9 \\
(19)\end{array}$ & $\begin{array}{l}0.8 \\
(5)\end{array}$ & $\begin{array}{c}0.6 \\
(25)\end{array}$ & $\begin{array}{c}1.8 \\
(42)\end{array}$ & $\begin{array}{l}0.3 \\
(5)\end{array}$ & $\begin{array}{c}1.1 \\
(28)\end{array}$ & $\begin{array}{c}1.2 \\
(22)\end{array}$ & $\begin{array}{l}0.3 \\
(7)\end{array}$ \\
\hline Chalcididae & $\begin{array}{c}0.9 \\
(62)\end{array}$ & $\begin{array}{c}0.7 \\
(15)\end{array}$ & $\begin{array}{l}1.3 \\
(8)\end{array}$ & $\begin{array}{c}0.9 \\
(35) \\
\end{array}$ & $\begin{array}{c}1.7 \\
(41) \\
\end{array}$ & $\begin{array}{l}0.1 \\
(2) \\
\end{array}$ & $\begin{array}{c}1.0 \\
(26) \\
\end{array}$ & $\begin{array}{c}0.9 \\
(18) \\
\end{array}$ & $\begin{array}{c}1.0 \\
(28) \\
\end{array}$ \\
\hline
\end{tabular}


Table 5. Parameter estimates from the top mixed effects generalized linear model (based on AIC model selection, see Table A-2) to explain invertebrate predator abundance based on Julian date, year, patch size, and patch ID. Note the intercept value represents the predicted predator abundance in large patches. We report $95 \%$ confidence intervals. ' * ' represents parameters that do not overlap with zero.

\begin{tabular}{|c|c|c|c|c|}
\hline Parameter & Estimate \pm SE & z & $\begin{array}{c}\text { 95\% Confidence } \\
\text { Interval }\end{array}$ & SD \\
\hline \multicolumn{5}{|l|}{ Random effect } \\
\hline Patch ID & & & & 1.05 \\
\hline \multicolumn{5}{|l|}{ Fixed effects } \\
\hline Intercept * & $5.66 \pm 0.44$ & 12.98 & $4.79,6.52$ & \\
\hline Julian Date * & $-0.021 \pm 0.0015$ & -14.01 & $-0.024,-0.018$ & \\
\hline Year 2016 & $0.32 \pm 0.29$ & 1.13 & $-0.24,0.89$ & \\
\hline Small Patch $\left(<16 \mathrm{~m}^{2}\right)$ * & $0.45 \pm 0.18$ & 2.47 & $0.093,0.81$ & \\
\hline Medium Patch $\left(16-28 m^{2}\right)$ * & $0.68 \pm 0.24$ & 2.96 & $0.21,1.16$ & \\
\hline
\end{tabular}


Table 6. Parameter estimates from top mixed effects generalized linear model (based on AIC model selection, see Table A-4) to explain parasitoid abundance based on landscape type, Julian date, year, and patch ID. Note the intercept value represents the predicted predator abundance in agricultural landscapes. We report 95\% confidence intervals. ' * ' represents parameters that do not overlap with zero.

\begin{tabular}{|c|c|c|c|c|}
\hline Parameter & Estimate $\pm S E$ & $z$ & $\begin{array}{c}95 \% \text { Confidence } \\
\text { Interval }\end{array}$ & SD \\
\hline \multicolumn{5}{|l|}{ Random effect } \\
\hline Patch ID & & & & 0.58 \\
\hline \multicolumn{5}{|l|}{ Fixed effects } \\
\hline Intercept & $0.74 \pm 0.70$ & 1.06 & $-0.65,2.12$ & \\
\hline Julian Date & $0.0034 \pm 0.0032$ & 1.08 & $-0.0029,0.0097$ & \\
\hline Year 2016 * & $-0.59 \pm 0.20$ & -3.02 & $-0.98,-0.20$ & \\
\hline Non-agricultural & $-0.030 \pm 0.18$ & -0.16 & $-0.40,0.34$ & \\
\hline Roadside * & $-0.55 \pm 0.19$ & -2.92 & $-0.94,-0.18$ & \\
\hline
\end{tabular}


Table 7. Infection rate of Ophryocystis elektroscirrha (OE), a protozoan parasite, from adults eclosing from collected $5^{\text {th }}$ instars originating from different landscape types. The parasite loads classified on a binary scale, with 0-3 (0-100 spores) $=$ moderate to no infection, and score 4-5 $(>100)=$ heavily infected

\begin{tabular}{lccc}
\hline Landscape & $\begin{array}{c}\text { Heavily Infected } \\
(4-5)\end{array}$ & $\begin{array}{c}\text { Moderate to no } \\
\text { infection (0-3) }\end{array}$ & \\
& 12 & 66 & $15 \%$ \\
\hline Agricultural & 5 & 11 & $31 \%$ \\
Roadside & 1 & 9 & $10 \%$ \\
Non-Agricultural & 18 & 86 & $17 \%$ \\
Total & & & \\
\hline
\end{tabular}




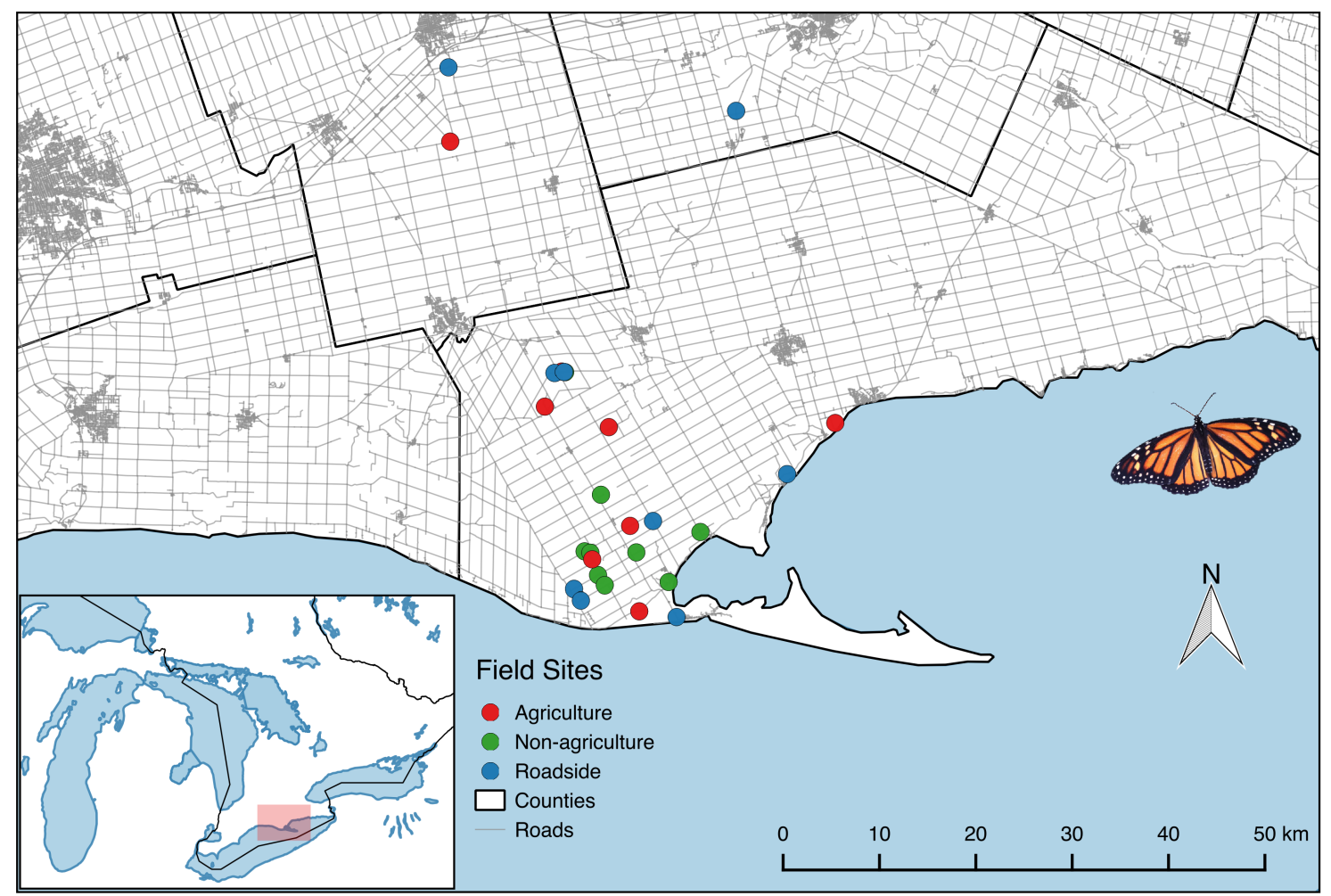

Figure 1. Map of study area showing field site locations colour coded by landscape type and the location of the study area within Ontario, Canada (red box in the inset map). 


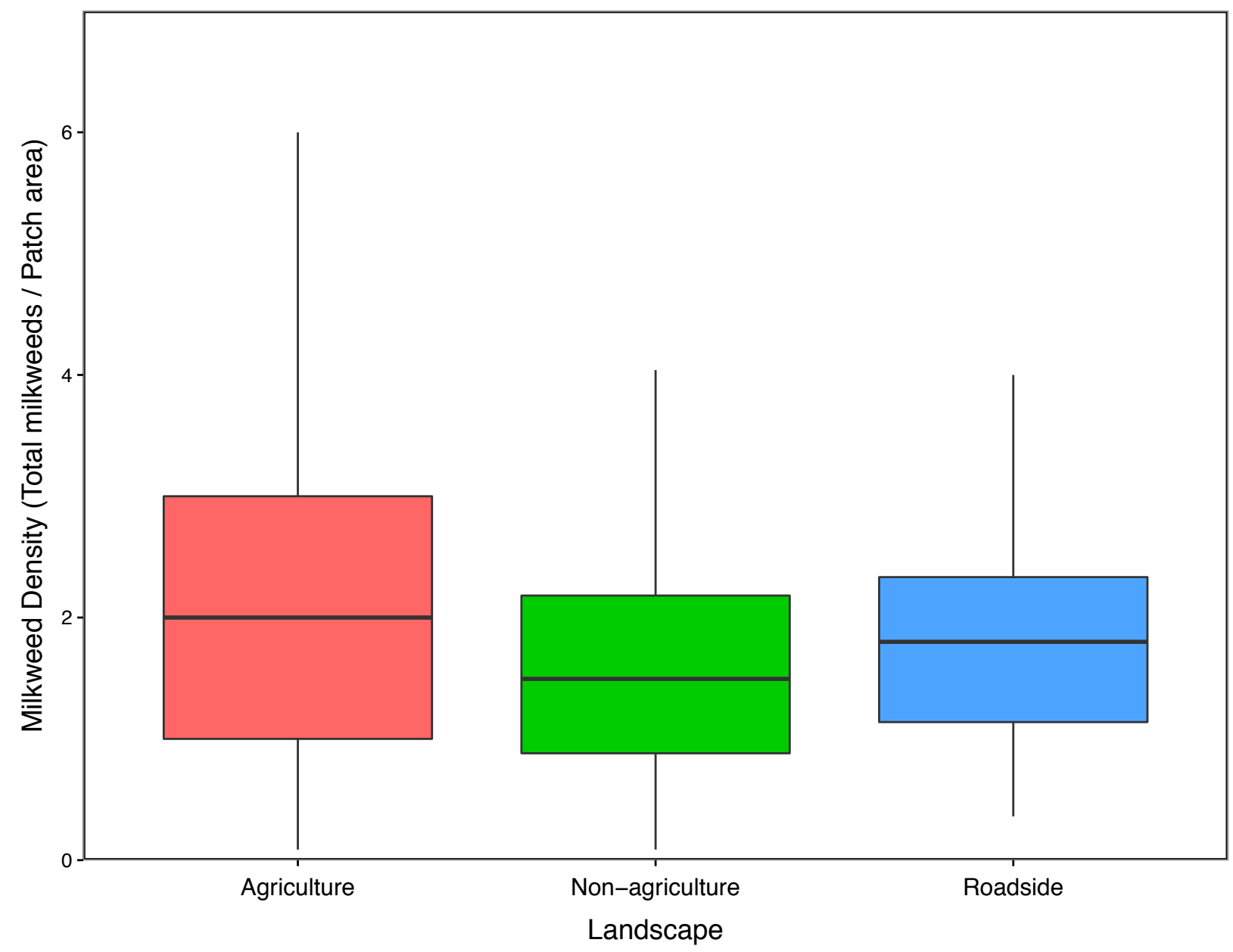

Figure 2. Milkweed density (total number of milkweed stems divided by the total area of the patch) in patches of milkweed in each landscape type (agriculture: $n=330$; non-agriculture: $n=$ 162; roadside: $n=170$ ). Outliers not shown (see fig. A-2). Box and whiskers plot are composed of lower and higher quartiles (boxes), non-outlier ranges (whiskers), and medians (middle lines). 


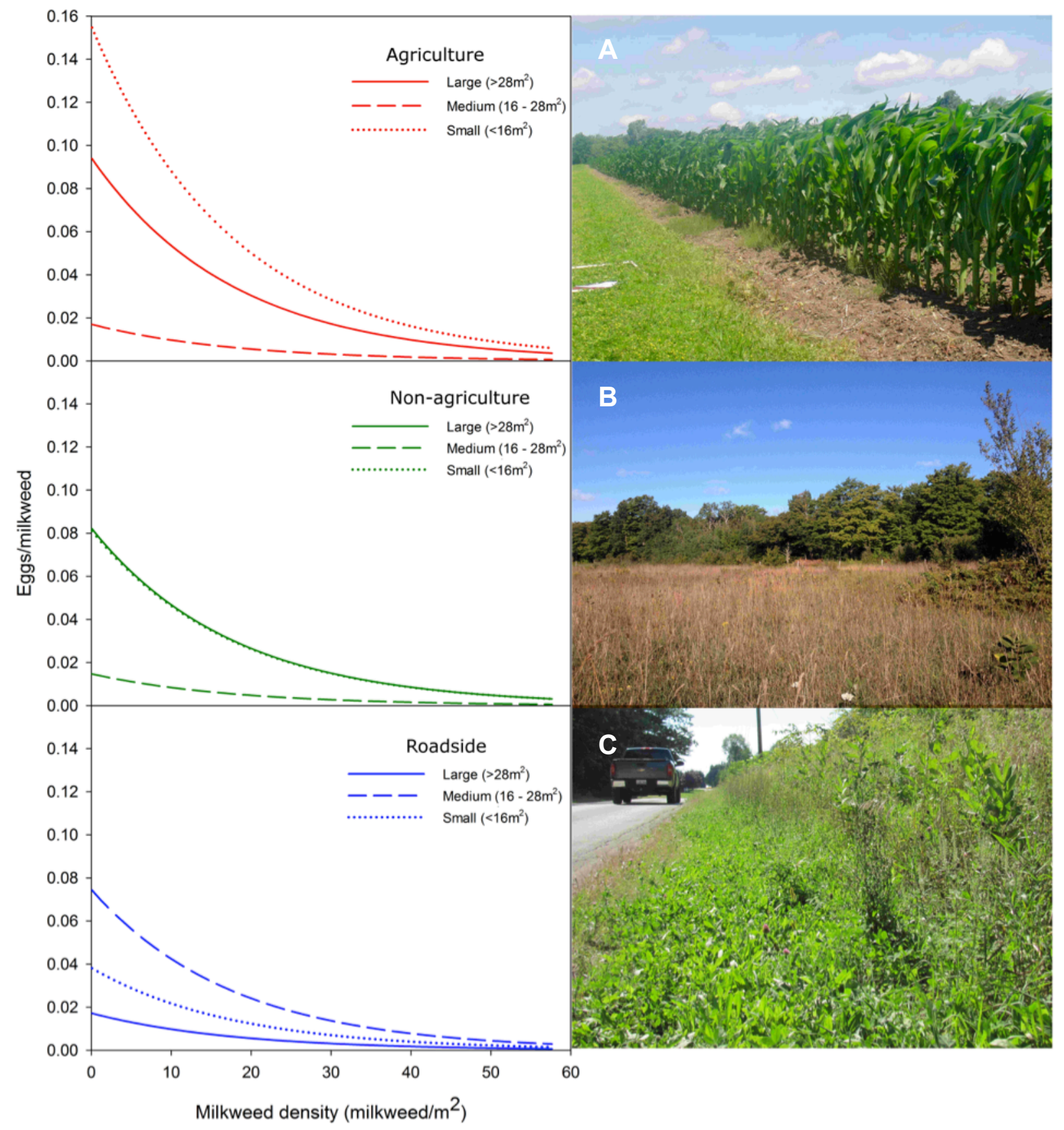

Figure 3. Predicted egg density (eggs/milkweed stem) in three landscape types (A, agriculture; B, non-agriculture; C, roadside) by patch size and milkweed density (milkweed stems $/ \mathrm{m}^{2}$ ) predicted from parameter estimates from the top model. Adjacent to each panel figure is a photographic example of a site in each associated landscape type. 


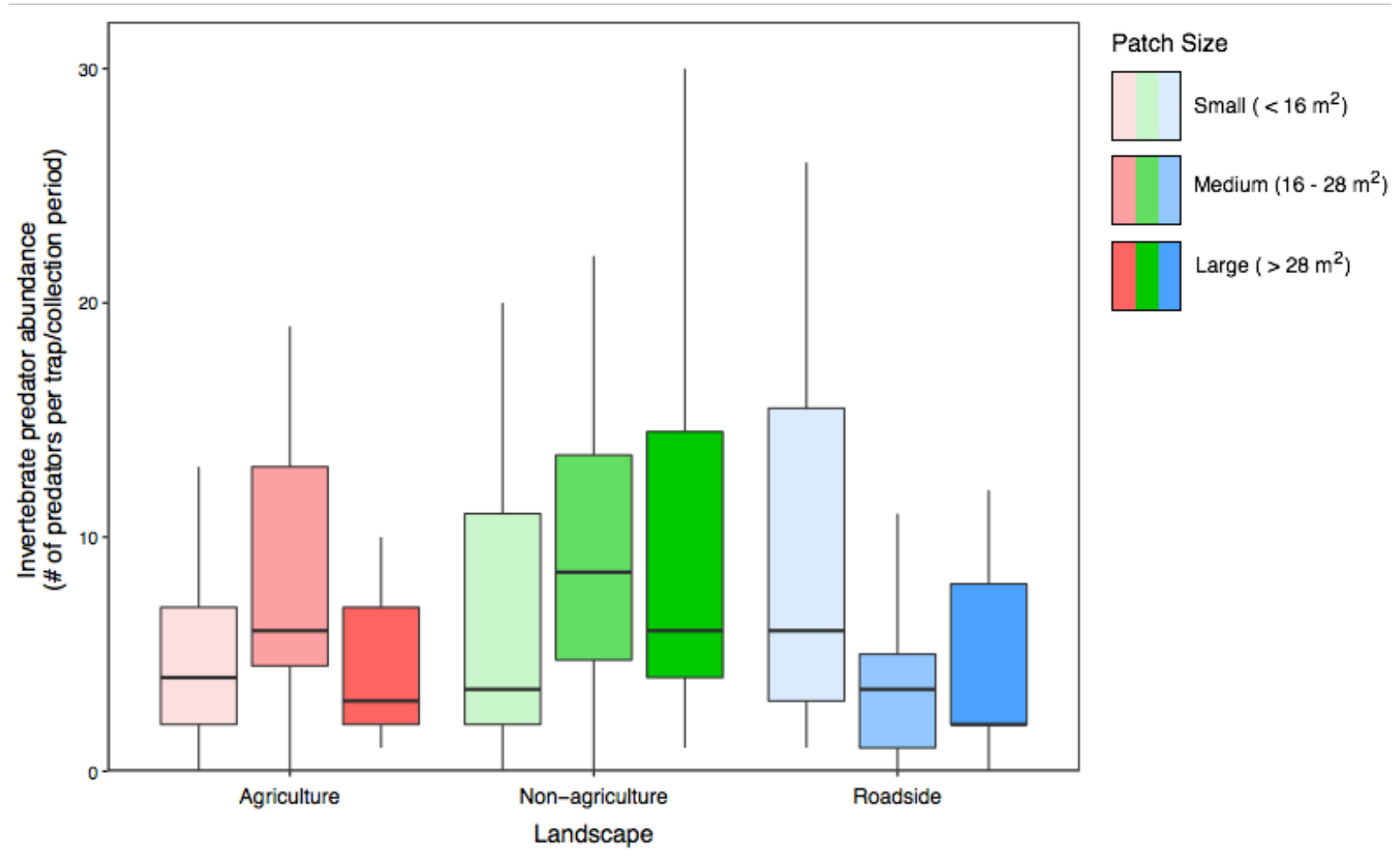

Figure 4. Invertebrate predator abundance (number of predators per trap sampled every other week) per each patch size and landscape type (agriculture, non-agriculture, roadside). Outliers not shown (see fig. A-3). Box and whiskers plot are composed of lower and higher quartiles (boxes), non-outlier ranges (whiskers), and medians (middle lines). 


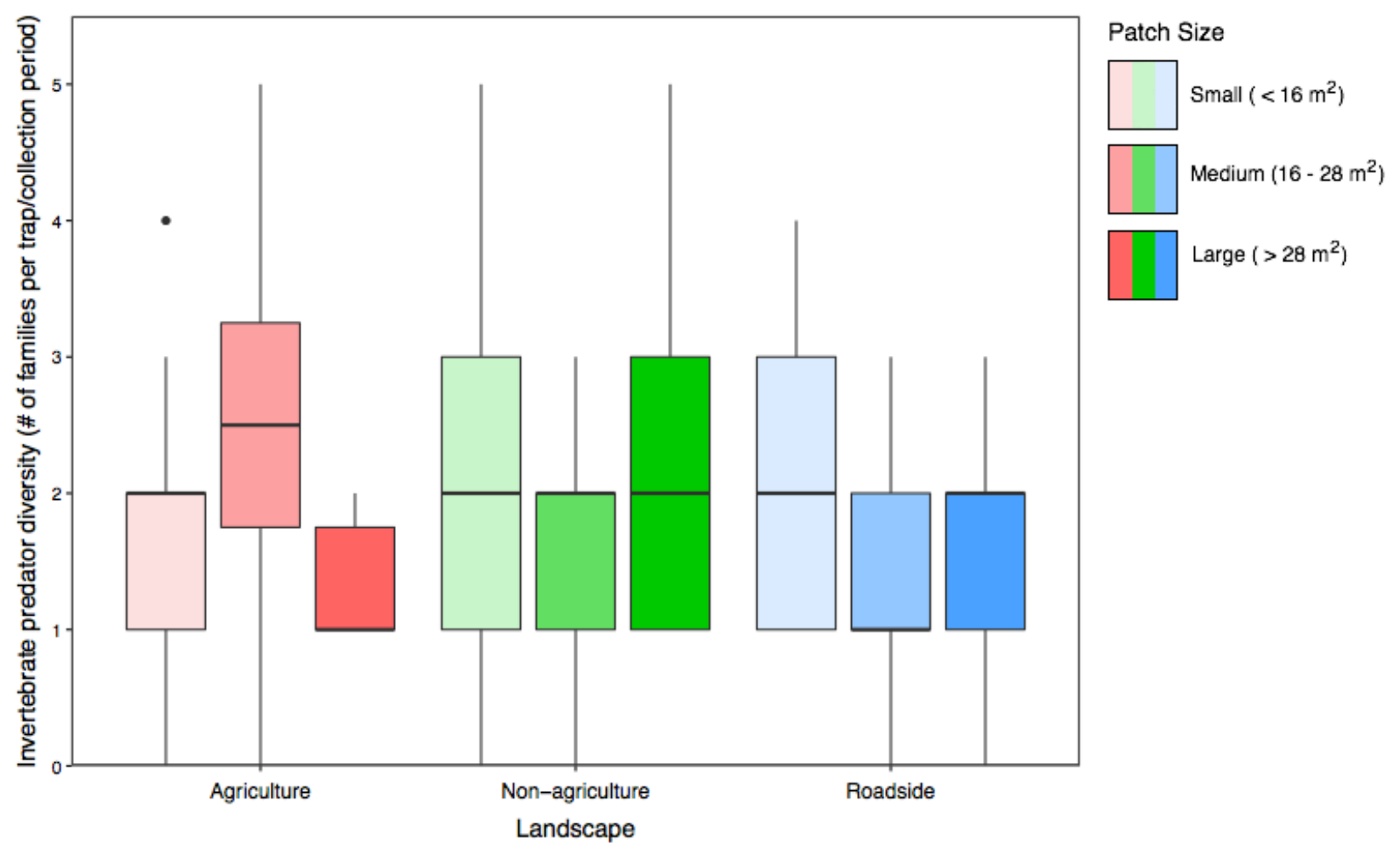

Figure 5. Invertebrate predator diversity (number of predator families present per trap sampled every other week) per each patch size and landscape type (agriculture, non-agriculture, roadside). Box and whiskers plots are composed of non-outlier ranges (whiskers), lower and higher quartiles (boxes) and medians (middle lines). Outliers are represented as dots. 


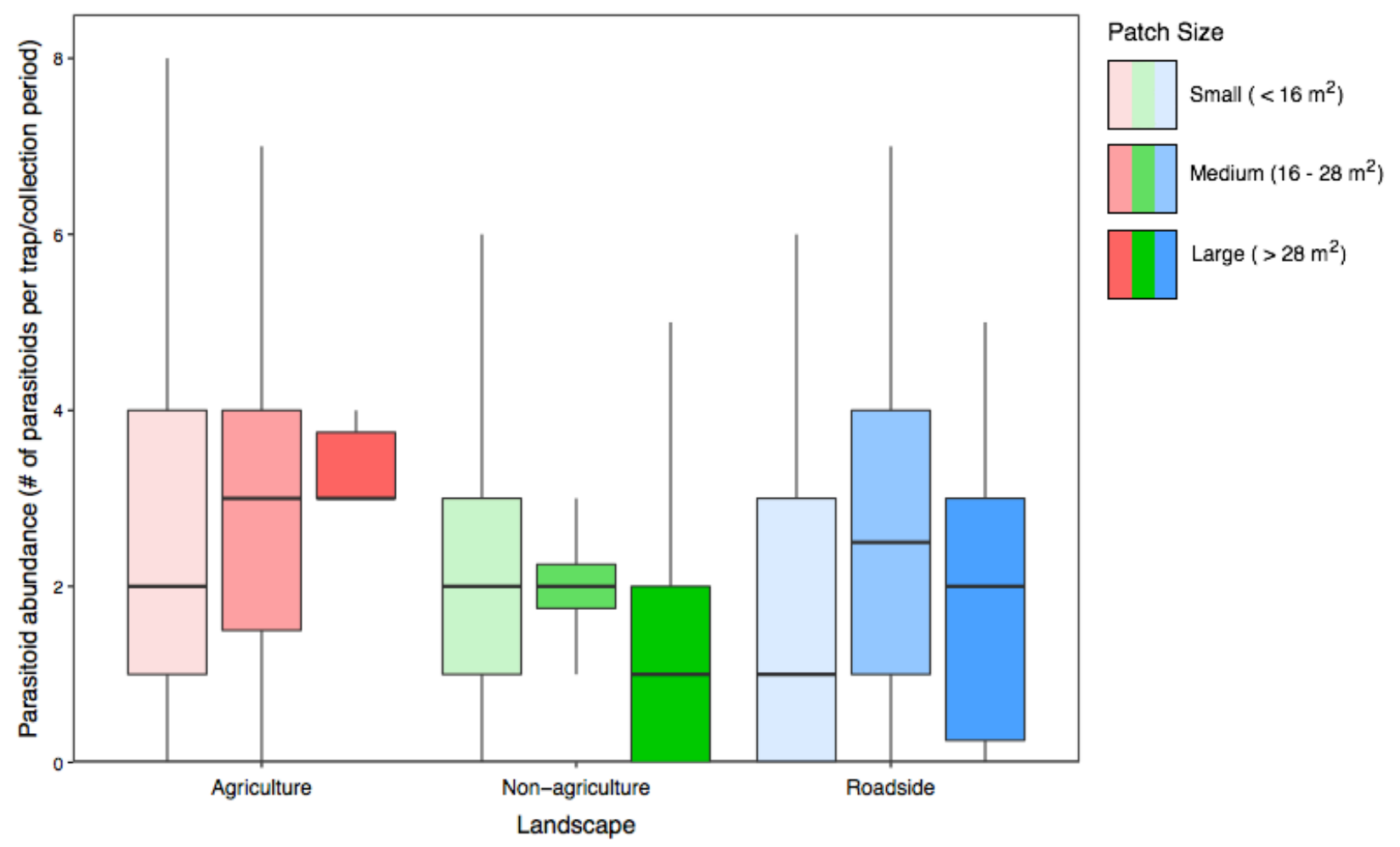

Figure 6. Parasitoid abundance (number of parasitoids per trap sampled every other week) per each patch size and landscape type (agriculture, non-agriculture, roadside). Outliers not shown (see fig. A-4). Box and whiskers plot are composed of lower and higher quartiles (boxes), nonoutlier ranges (whiskers), and medians (middle lines). 


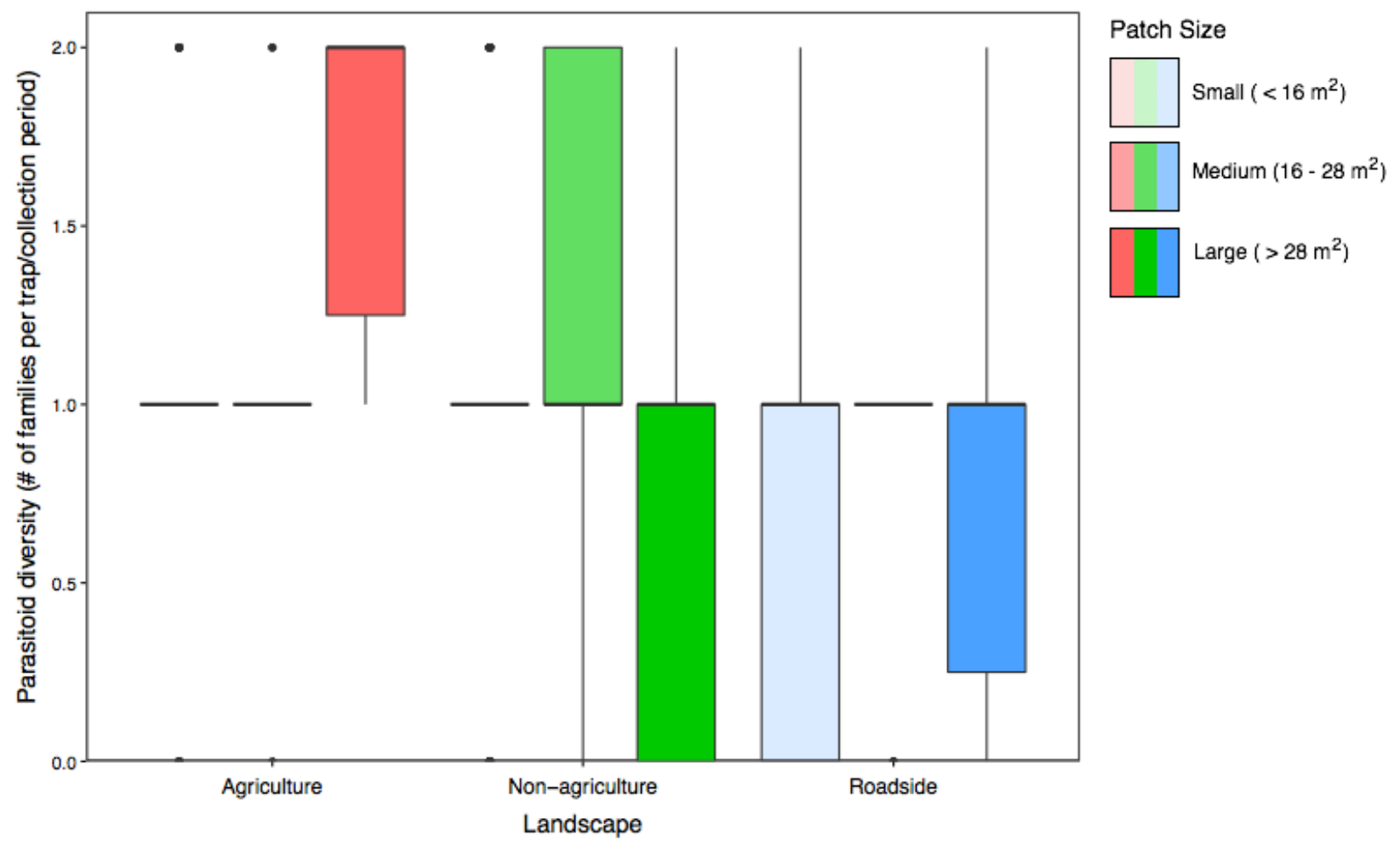

Figure 7. Parasitoid diversity (number of parasitoid families present per trap sampled every other week) per each patch size and landscape type (agriculture, non-agriculture, roadside). Box and whiskers plots are composed of non-outlier ranges (whiskers), lower and higher quartiles (boxes) and medians (middle lines). Outliers are represented as dots. 


\section{REFERENCES}

Altizer, S.M., and Oberhauser, K.S. 1999. Effects of the protozoan parasite, Ophryocystis elektroscirrha, on the fitness of monarch butterflies (Danaus plexippus). Journal of Invertebrate Pathology 74: 76-88.

Altizer, S. M., Oberhauser, K. S., and Brower, L. P. 2000. Associations between host migration and the prevalence of a protozoan parasite in natural populations of adult monarch butterflies. Ecological Entomology 25: 125-139.

Altizer, S. M., Hobson, K. A., Davis, A. K., De Roode, J. C., and Wassenaar, L. I. 2015. Do healthy monarchs migrate farther? Tracking natal origins of parasitized vs. uninfected monarch butterflies overwintering in Mexico. Public Library of Science, One 10: e0141371.

Arnaud, P. H., Jr. 1978. A host-parasite catalog of North American Tachinidae (Diptera). U.S. Department of Agriculture Miscellaneous Publication No. 1319. Washington, D. C.: U.S. Department of Agriculture.

Åström, M., Pettersson, L. B., Öckinger, E., and Hedin, J. 2013. Habitat preferences and conservation of the marbled jewel beetle Poecilonota variolosa (Buprestidae). Journal of Insect Conservation 17: 1145-1154.

Bartel, R. A., Oberhauser, K. S., De Roode, J. C., and Altizer, S. M. 2011. Monarch butterfly migration and parasite transmission in eastern North America. Ecological Society of America 92: 342-351.

Bates, D., Mächler, M., Bolker, B. M., and Walker, S. C. 2015. Fitting linear mixed-effects models using lme4. Journal of Statistical Software 67: 1-48. 
Battin, J. 2004. When good animals love bad habitats: ecological traps and the conservation of animal populations. Conservation Biology 18: 1482-1491.

Bergin, T. M., Best, L. B., Freemark, K. E., and Koehler, K, J. 2000. Effects of landscape structure on nest predation in roadsides of a midwestern agroecosystem: A multiscale analysis. Landscape Ecology 15: 131-143.

Bergström, G., Rothschild, M., Groth, I., and Crighton, C. 1994. Oviposition by butterflies on young leaves: investigation of leaf volatiles. Chemoecology 5: 147-158.

Bianchi, F. J. J. A., Booji, C. J. H., and Tscharnetke, T. 2006. Sustainable pest regulation in agricultural landscapes: A review on landscape composition, biodiversity and natural pest control. Proceedings of the Royal Society of London B: Biological Sciences 273: 17151727.

Bolker, B. M., Brooks, M. E., Clark, C. J., Geange, S. W., Poulsen, J. R., Stevens, M. H. H. and White, J. S. S. 2009. Generalized linear mixed models: a practical guide for ecology and evolution. Trends in Ecology and Evolution: 24: 27-135.

Borkin, S. S. 1982. Notes on shifting distribution patterns and survival of immature Danaus plexippus (Lepidoptera: Danaidae) on the food plant Asclepias syriaca. Great Lakes Entomologist 15: 199-206.

Boyce, M. S., Mao, J. S., Merrill, E. H., Fortin, D., Turner, M. G., Fryxell, J., and Turchin, P. 2003. Scale and heterogeneity in habitat selection by elk in Yellowstone National Park. Ecoscience 10: 421-431.

Brady, S. P., and Richardson, J. L. 2017. Road ecology: shifting gears toward evolutionary perspectives. Frontiers in Ecology and the Environment 15: 91-98. 
Brower, L. P. 1995. Understanding and misunderstanding the migration of the monarch butterfly (Nymphalidae) in North America: 1857-1995. Journal of the Lepidopterists' Society 49:304-385.

Brower, L. P. 1996. Monarch butterfly orientation: missing pieces of a magnificent puzzle. Journal of Experimental Biology 199: 93-103.

Brower, L. P., Taylor, O. R., Williams, E. H., Slayback, D. A., Zubieta, R. R., and Ramierz, M. I. 2012. Decline of monarch butterflies overwintering in Mexico: is the migratory phenomenon at risk? Insect Conservation and Diversity 5: 95-100.

Bruce, T. J. A., Wadhams, L. J., and Woodcock, C. M. 2005. Insect host location: a volatile solution. Trends in Plant Science 10: 269-274.

Bull, C. M., Zalucki, M.P., Suzuki, Y., Mackay, D. A, and Kitching, R.I. 1985. An experimental investigation of patch use by female monarch butterflies, Danaus plexippus. Australian Journal of Ecology 10: 391-398.

Burnham, K.P., and Anderson, D. R. 2002. Model selection and multimodel inference: A practical information-theoretic approach, 2nd. New York, NY: Springer-Verlag New York, Inc.

Calvert, W. H. 2004. The effects of fire ants on monarch breeding in Texas. In The monarch butterfly: Biology and conservation (eds KS Oberhauser, MJ Solensky), pp. 47-53. Ithaca, NY: Cornell University Press.

Camaclang, A. E., Maron, M., Martin, T. G., and Possingham, H. P. 2015. Current practices in the identification of critical habitat for threatened species. Conservation Biology 29: 482492. 
Ceballos, G. and Ehrlich, P.R. 2002. Mammal population losses and the extinction crisis. Science 296: 904-907.

Clancy, K. M. 1992. Reponse of western spruce budworm (Lepidoptera: Tortricidae) to increased nitrogen in artificial diets. Environmental Entomology 21: 331-344.

Cockrell, B. J., Malcolm, S. B., and Brower, L. P. 1993. Time, temperature, and latitudinal constraints on the annual recolonization of eastern North America by the monarch butterfly. In Biology and conservation of the monarch butterfly (eds SB Malcolm, MP Zalucki), pp. 233-251. Los Angeles, CA: Natural History Museum of Los Angeles County; Science Series.

Cohen, J., and Brower, L. 1982. Oviposition and larval success of wild monarch butterflies (Lepidoptera: Danaidae) in relation to host plant size and cardenolide concentration. Journal of the Kansas Entomological Society 55: 343-348.

Craine, J. M., Fargione, J., and Sugita, S. 2005. Supply pre-emption, not concentration reduction, is the mechanism of competition for nutrients. New Phytologist 166: 933-940.

Davis, S. K. 2004. Area sensitivity in grassland passerines: Effects of patch size, patch shape, and vegetation structure on bird abundance and occurrence in southern Saskatchewan. The Auk 121: 1130-1145.

De Anda, A., and Oberhauser, K. S. 2015. Invertebrate natural enemies and stage-specific mortality rates of monarch eggs and larvae. In Monarchs in a changing world: Biology and conservation of an iconic butterfly (eds KS Oberhauser, KR Nail, S Altizer), pp. 6070. Ithaca, NY: Cornell University Press. 
DeCesare, N. J., Hebblewhite, M., Bradley, M., Hervieux, D., Neufeld, L., and Musiani, M. 2014. Linking habitat selection and predation risk to spatial variation in survival. Journal of Animal Ecology 83: 343-352.

De Roode, J. C., Gold, L. R., and Altizer, S. 2007. Virulence determinants in a natural butterfly-parasite system. Parasitology 134: 657-668.

Duke, S. O., and Powles, S. B. 2008. Glyphosate: a once-in-a-century herbicide. Pest Management Science 64: 319-325.

Dwernychuk, L. W., and D. A. Boag. 1972. Ducks nesting in association with gulls - an ecological trap? Canadian Journal of Zoology 50: 559-563.

Fahrig, L. 1997. Relative effects of habitat loss and fragmentation on population extinction. The Journal of Wildlife Management 61: 603-610.

Finch, S., and Collier, R. H. 2000. Host plant selection by insects-a theory based on 'appropriate/inappropriate landings' by pest insects of cruciferous plants. Entomologia Experimentalis et Applicata 96: 91-102.

Fischer, K., and Fiedler, K. 2000. Response of the copper butterfly Lycaena tityrus to increased leaf nitrogen in natural food plants: Evidence against the nitrogen limitation hypothesis. Oecologia 124: 235-241.

Flockhart, D. T. T., Martin, T. G., Norris, D. R. 2012. Experimental examination of intraspecific density-dependent competition during the breeding period in monarch butterflies (Danaus plexippus). Public Library of Science, One 7: e45080. doi: 10.1371/journal.pone.0045080

Flockhart, D. T. T., Wassenaar, L. I., Martin, T. G., Hobson, K. A., Wunder, M. B., and Norris, D. R. 2013. Tracking multi-generational colonization of the breeding grounds by 
monarch butterflies in eastern North America. Proceedings of the Royal Society of London B: Biological Sciences 280: 20131087; doi: 10.1098/rspb.2013.1087.

Flockhart, D. T. T., Pichancourt, J-B., Norris, D. R., and Martin, T. G. 2015. Unravelling the annual cycle in a migratory animal: breeding-season habitat loss drives population declines of monarch butterflies. Journal of Animal Ecology 84: 155-165.

Flockhart, D. T. T., Brower, L. P., Ramirez, M. I., Hobson, K. A., Wassenaar, L. I., Altizer, S., and Norris, D. R. 2017. Regional climate on the breeding grounds predicts variation in the natal origin of monarch butterflies overwintering in Mexico over 38 years. Global Change Biology. In press doi: 10.1111/gcb.13589

Foit, J., Kašák, J., and Nevoral, J. J. 2016. Habitat requirements of the endangered longhorn beetle Aegosoma scabricorne (Coleoptera: Cerambycidae): A possible umbrella species for saproxylic beetles in European lowland forests. Insect Conservation 20: 837-844.

Freemark, K. E., and Merriam, H. G. 1986. Importance of area and habitat heterogeneity to bird assemblages in temperate forest fragments. Biological Conservation 36: 115-141.

Fulton, B. B. 1940. The hornworm parasite, Apanteles congregatus (Say) and the hyperparasite, Hypopteromalus tabacum (Fitch). Annals of the Entomological Society of America 33: 231-244.

Gibo, D. L., and Pallett, M. J. 1979. Soaring flight of monarch butterflies, Danaus plexippus (Lepidoptera: Danaidae), during the late summer migration in southern Ontario. Canadian Journal of Zoology. 57: 1393-1401.

Gilbert, F., and Jervis, M. 1998. Functional, evolutionary and ecological aspects of feedingrelated mouthpart specializations in parasitoid flies. Biological Journal of the Linnean Society 63: 495-535. 
Goulson, D. 2013. An overview of the environmental risks posed by neonicotinoid insecticides. Journal of Applied Ecology 50: 977-987.

Hartzler, G., and Buhler, D. D. 2000. Occurrence of common milkweed (Asclepias syriaca) in cropland and adjacent areas. Crop Protection 19: 363-366.

Hartzler, G. 2010. Reduction in common milkweed (Asclepias syriaca) occurrence in Iowa cropland from 1999 to 2009. Crop Protection 29: 1542-1544.

Heikkinen, R. K., Luoto, M., Virkkala, R., and Rainio, K. 2004. Effects of habitat cover, landscape structure and spatial variables on the abundance of birds in an agriculturalforest mosaic. Journal of Applied Ecology 41: 824-835.

Hunter, J. E., Gutiérrez, R. J., and Franklin, A. B. 1995. Habitat configuration around spotted owl sites in northwestern California. The Condor 97: 684-693.

Huxel, G. R., and Hastings, A. 1999. Habitat loss, fragmentation, and restoration. Restoration Ecology 7: 309-315.

Inamine, H., Ellner, S. P., Springer, J. P., and Agrawal, A. A. 2016. Linking the continental migratory cycle of the monarch butterfly to understand its population decline. Oikos 125 : 1081-1091.

Johnson, D. H. 1980. The comparison of usage and availability measurements for evaluating resource preference. Ecology 61: 65-71.

Kareiva, P., and Wennergren, U. 1995. Connecting landscape patterns to ecosystem and population processes. Nature 373: 299-302.

Kasten, K., Stenoien, C., Caldwell, W., and Oberhauser, K. 2016. Can roadside habitat lead monarchs on a route to recovery? Journal of Insect Conservation 20: 1047-1057. doi:10.1007/s10841-016-9938-y 
Kerr, J.T., and Cihlar, J. 2004. Patterns and causes of species endangerment in Canada. Ecological Applications 14: 743-753.

Kirk, W. D. J. 1984. Ecologically selective coloured traps. Ecological Entomology 9: 35-41.

Koch, R. L., Hutchison, W. D., Venette, R. C., Heimpel, G. E. 2003. Susceptibility of immature monarch butterfly, Danaus plexippus (Lepidoptera: Nymphalidae: Danainae), to predation by Harmonia axyridis (Coleoptera: Coccinellidae). Biological Control 8: 265270.

Koch, R. L., Venette, R. C., and Hutchison, W. D. 2005. Influence of alternative prey on predation of monarch butterfly (Lepidoptera: Nymphalidae) larvae by the multicolored Asian lady beetle (Coleoptera: Coccinellidae). Environmental Entomology 34: 410-416.

Krupke, C. H., Hunt, G. J., Eitzer, B. D., Andino, J., and Given, K. 2012. Multiple routes of pesticide exposure for honey bees living near agricultural fields. The Public Library of Science, One 7:e29268

Lagerwerff, J. V. 1970. Contamination of roadside soil and vegetation with cadmium, nickel, lead, and zinc. Environmental Science \& Technology 4: 583-586.

Lawton, J. H. 1983. Plant architecture and the diversity of phytophagous insects. Annual Review of Entomology 28: 23-39.

Lee, J. C., Heimpel, G. E., and Leibee, G. L. 2004. Comparing floral nectar and aphid honeydew diets on the longevity and nutrient levels of a parasitoid wasp. Entomologia Experimentalis et Applicata 111: 189-199.

Leong, K.L.H., Yoshimura, M.A., Kaya, H.K. and Williams, H. 1997. Instar susceptibility of the monarch butterfly (Danaus plexippus) to the neogregarine parasite, Ophryocystis elektroscirrha. Journal of Invertebrate Pathology 69: 79-83. 
Lewis, C. A., Lester, N. P., Bradshaw, A. D., Fitzgibbon, J. E., Fuller, K., Hakanson, L., and Richards, C. 1996. Considerations of scale in habitat conservation and restoration. Canadian Journal of Fisheries and Aquatic Sciences 53:440 445.

Lewis, W. J., Stapel, J. O., Cortesero, A. M., and Takasu, K. 1998. Understanding how parasitoids balance food and host needs: importance to biological control. Biological Control 11: 175-183.

Malcolm, S.B. and Brower, L.P., 1986. Selective oviposition by monarch butterflies (Danaus plexippus L.) in a mixed stand of Asclepias curassavica L. and A. incarnata L. in south Florida. Journal of the Lepidopterists' Society 40: 255-263.

Malcolm, S. B., Cockrell, B. J., and Brower, L. P. 1993. Spring recolonization of eastern North America by the monarch butterfly: successive brood or single sweep migration? In Biology and conservation of the monarch (eds SB Malcolm, MP Zalucki), pp. 253-267. Los Angeles, CA: Natural History Museum of Los Angeles County; Science Series.

Marshall, S. A. 2007. Insects: Their natural history and diversity. New York, NY: Firefly Press Ltd.

Marshall, S. A. 2012. Flies: The natural history and diversity of Diptera. New York, NY: Firefly Press Ltd.

Matter, S. F. 1996. Interpatch movement of the red milkweed beetle, Tetraopes tetraophthalmus: individual responses to patch size and isolation. Oecologia 105: 447-453.

Mayor, S. J., Schneider, D. C., Schaefer, J. A., and Mahoney, S. P. 2009. Habitat selection at multiple scales. Ecoscience 16: 238-247.

Mazerolle, M. J., and Villard, M. A. 1999. Patch characteristics and landscape context as predictors of species presence and abundance: A review. Ecoscience 6: 117-124. 
McKenna, D. D., McKenna, K. M., Malcom, S. B., and Berenbaum, M. R. 2001. Mortality of Lepidoptera along roadways in central Illinois. Journal of the Lepidopterists' Society 55: 63-68.

McLaughlin, R. E., and Myers, J. 1970. Ophryocystis elektroscirrha sp. n., a neogregarine pathogen of the monarch butterfly Danaus plexippus (L.) and the Florida queen butterfly Danaus gilippus berenice Cramer. Journal of Protozoology 17: 300-305.

Miller, N. G., Wassenaar, L. I., Hobson, K. A., and Norris, D. R. 2012. Migratory connectivity in the Monarch butterfly: patterns of spring re-colonization in eastern North America. Public Library of Science, One 3: e39891.

Misenhelter, M.D., and Rotenberry, J.T. 2000. Choices and consequences of habitat occupancy and nest site selection in sage sparrows. Ecology 81: 2892-2901.

Munguira, M. L., and Thomas, J. A. 1992. Use of road verges by butterfly and burnet populations, and the effect of roads on adult dispersal and mortality. Journal of Applied Ecology 29: 316-329.

Murdoch, W. W., Evans, F. C., and Peterson, C. H. 1972. Diversity and pattern in plants and insects. Ecology 53: 819-829.

Murphy, D. D., Menninger, M. S., and Ehrlich, P. R. 1984. Nectar source distribution as a determinant of oviposition host species in Euphydryas chalcedona. Oecologia 62: 269271.

Myers, J. H. 1985. Effect of physiological condition of the host plant on the oviposition choice of cabbage white butterfly, Pieris rapae. Journal of Animal Ecology 54: 193-204.

Myers, J. H, Post, B. J. 1981. Plant nitrogen fluctuations of insect populations: a test with the cinnebar moth-tansy ragwort system. Oecologia 48:151-156. 
Nail, K. R., Stenoien, C., and Oberhauser, K. S. 2015. Immature monarch survival: effects of site characteristics, density, and time. Annals of the Entomological Society of America 108: 680-690.

Oberhauser, K. S. 2004. Overview of monarch breeding biology. In The monarch butterfly: Biology and conservation (eds KS Oberhauser, MJ Solensky), pp.1 - 3. Ithaca, NY: Cornell University Press.

Oberhauser, K. S. 2012. Tachinid flies and monarch butterflies: Citizen scientists document parasitism patterns over broad spatial and temporal scales. American Entomologist 58: $19-22$.

Oberhauser, K., and D. Frey. 1999. Coercive mating by overwintering male monarch butterflies. In The monarch butterfly: Biology and conservation (eds KS Oberhauser, MJ Solensky), pp. 61 - 68. Ithaca, NY: Cornell University Press.

Oberhauser, K. S., and Kuda, K. 1997. Field guide to monarch caterpillars (Danaus plexippus). Monarchs in the classroom. Saint Paul, MN: University of Minnesota.

Oberhauser, K. S., Prysby, M. D., Mattila, H. R., Stanley-Horn, D. E., Sears, M. K., Dively, G., Olson, E., Pleasant, J. M., Lam, W. F., and Hellmich R. L. 2001. Temporal and spatial overlap between monarch larvae and corn pollen. Proceedings of the National Academy of Sciences of the United States of America 98: 11913 -11918.

Oberhauser, K. S., Anderson, M., Anderson, S., Caldwell, W., De Anda, A., Hunter, M., Kaiser, M. C., and Solensky, M. J. 2015. Lacewings, wasps, and flies - Oh my. In Monarchs in a changing world: Biology and conservation of an iconic butterfly (eds KS Oberhauser, KR Nail, S Altizer), pp. 71-82. Ithaca, NY: Cornell University Press. 
O’Brien, D., Manseau, M., Fall, A., Fortin, M-J. 2006. Testing the importance of spatial configuration of winter habitat for woodland caribou: An application of graph theory. Biological Conservation 130: 70-83.

O'Hara, J. E. 1999. Tachinidae (Diptera) parasitoids of bertha armyworm (Lepidoptera: Noctuidae). The Canadian Entomologist 131: 11-28.

Oyeyele, S. O., and Zalucki, M. P. 1990. Cardiac glycosides and oviposition by Danaus plexippus on Asclepias fruticosa in south-east Queensland (Australia), with notes on the effect of plant nitrogen content. Ecological Entomology 15: 177-185.

Padgette, S. R., Re, D. B., Barry, G. F., Eichholtz, E. D., Delannay, X., Fuchs, R. L., Kishore, G. M., and Fraley, R. T. 1996. New weed control opportunities: Development of soybeans with a Roundup Ready ${ }^{\mathrm{TM}}$ gene. In Herbicide-resistant crops. (ed by SO Duke), pp. 5384. Boca Raton, FL: CRC Press.

Parsons, J. A. 1965. A digitalis-like toxin in the monarch butterfly, Danaus plexippus L. Journal of Physiology. 178: 290-304.

Patt, J. M., Hamilton, G. C., and Lashomb, J. H. 1997. Foraging success of parasitoid wasps on flowers: interplay of insect morphology, floral architecture and searching behavior. Entomologia Experimentalis et Applicata 83: 21-30.

Pecenka, J. R. and Lundgren, J. G. 2015. Non-target effects of clothianidin on monarch butterflies. The Science of Nature 102: 1-4.

Pereboom, V., Mergey, M., Villerette, N., Helder, R., Gerald, J-F., and Lodé, T. 2008. Movement patterns, habitat selection, and corridor use of a typical woodland-dweller species, the European pine marten (Martes martes), in fragmented landscape. Canadian Journal of Zoology 86: 983-991. 
Pimm, S. L, and Raven, P. 2000. Extinction by numbers. Nature 403: 843-845.

Pleasants, J. M. 2017. Milkweed restoration in the Midwest for monarch butterfly recovery: Estimates of milkweeds lost, milkweeds remaining and milkweeds that must be added to increase the monarch population. Insect Conservation and Diversity 10: 42-53.

Pleasants, J. M., and Oberhauser, K. S. 2013. Milkweed loss in agricultural fields because of herbicide use: effect on the monarch butterfly population. Insect Conservation and Diversity 6: 135-144.

Prysby, M. D. 2004. Natural enemies and survival of monarch eggs and larvae. In The monarch butterfly: Biology and conservation (eds KS Oberhauser, MJ Solensky), pp. 27 - 37. Ithaca, NY: Cornell University Press.

Pulliam, H. R., Dunning, J. B., and Liu, J. 1992. Population dynamics in complex landscapes: A case study. Ecological Applications 2:165 177.

Quevedo, M., Bañuelos, M. J., and Obeso, J. R. 2006. The decline of Cantabrain capercaillie: How much does habitat configuration matter? Biological Conservation 127: 190-200.

R Development Core Team. 2017. R: a language and environment for statistical computing. Version 3.3-1. R Foundation for Statistical Computing, Vienna, Austria. http://www.rproject.org/

Raynaud, X., and Leadley, P. W. 2004. Soil characteristics play a key role in modeling nutrient competition in plant communities. Ecology 85: 2200-2214.

Rayor, L. S. 2004. Effects of monarch larval host plant chemistry and body size on Polistes wasp predation. In The monarch butterfly: Biology and conservation (eds KS Oberhauser, MJ Solensky), pp. 39-46. Ithaca, NY: Cornell University Press. 
Reich, P., Wright, I., Cavender-Bares, J., Craine, J., Oleksyn, J., Westoby, M., and Walters, M. 2003. The evolution of plant functional variation: traits, spectra, and strategies. International Journal of Plant Sciences 164: S143-S164.

Ries, L., Debinski, D. M., and Wieland, M. L. 2001. Conservation value of roadside prairie restoration to butterfly communities. Conservation Biology 15: 401-411.

Rothschild, M., Reichstein, T., Parsons, J., and Aplin, R. 1966. Poisons in aposematic insects. Royal Society Conversazione: 10.

Satterfield, D. A., Maerz, J. C., and Altizer, S. 2015. Loss of migratory behaviour increases infection risk for a butterfly host. Proceedings of the Royal Society of London B: Biological Sciences 282: 20141734.

Scanlon, P. F. 1987. Heavy metals in small mammals in roadside environments: implications for food chains. Science of the Total Environment 59: 317-323.

Schadt, S., Knauer, F., Kaczensky, P., Revilla, E., Wiegand, T., and Trepl, L. 2002. Rule-based assessment of suitable habitat and patch connectivity for the Eurasian lynx. Ecological Applications 12: 1469-1483.

Schaffner, J. V. and Griswold, C. L. 1934. Macrolepidoptera and their parasites reared from field collections in the northeastern part of the United States (No. 188). Washington, DC: US Department of Agriculture.

Semmens, B. X., Semmens, D. J., Thogmartin, W. E., Wiederholt, R., López-Hoffman, L., Diffendorfer, J. E., Pleasants, J. M., Oberhauser, K. S., and Taylor, O. R. 2016. Quasiextinction risk and population targets for the eastern, migratory population of monarch butterflies (Danaus plexippus). Scientific Reports 6: 1-7. 
Slansky, F., and Feeny, P. 1977. Stabilization of the rate of nitrogen accumulation by larvae of the cabbage butterfly on wild and cultivated foodplants. Ecological Monographs 47: 209228.

Snell-Rood, E. C., Espeset, A., Boser, C. J., White, W. A., and Smykalski, R. 2014. Anthropogenic changes in sodium affect neural and muscle development in butterflies. Proceedings of the National Academy of Sciences 111: 10221-10226.

Southwood, T. R., Brown, V. K., and Reader, P. M. 1979. The relationships of plant and insect diversities in succession. Biological Journal of the Linnean Society 12: 327-348.

Stenoien, C., McCoshum, S., Caldwell, W., De Anda, A., and Oberhauser, K. 2015. New reports that monarch butterflies (Lepidoptera: Nymphalidae, Danaus plexippus Linnaeus) are hosts for a pupal parasitoid (Hymenoptera: Chalcidoidae, Pteromalus cassotis Walker). Journal of the Kansas Entomological Society 88: 16-26.

Stenoien, C., Nail, K. R., Zalucki, J. M., Parry, H., Oberhauser, H. P., and Zalucki, M. P. 2016. Monarchs in decline: A collateral landscape level effect of modern agriculture. Insect Science. In press. doi: 10.1111/1744-7917.12404.

Tabashnik, B. E . 1982. Responses of pest and non-pest Colias butterfly larvae to intraspecific variation in leaf nitrogen and water content. Oecologia 55: 389-394.

Tahvanainen, J. O., and Root, R. B. 1972. The influence of vegetational diversity on the population ecology of a specialized herbivore, Phyllotreta cruciferae (Coleoptera: Chrysomelidae). Oecologia 10: 321-346.

Taylor, M. F. J. 1984. The dependence of development and fecundity of Samea multiplicalis on early larval nitrogen intake. Journal of Insect Physiology 30: 779-785. 
Taylor, O. R. and Shields, J. 2000. The summer breeding habitat of monarch butterflies in eastern North America. Environmental Protection Agency, Washington.

Thorsteinson, A. J. 1960. Host selection in phytophagous insects. Annual Review of Entomology 5: 193-218.

Tomizawa, M., Casida, J. E. 2005. Neonicotinoid insecticide toxicology: mechanisms of selective action. Annual Review of Pharmacology and Toxicology 45:247-268.

Triplehorn, C. A., and Johnson, N. F. 2005. Borror and DeLong's introduction to the study of insects, $7^{\text {th }}$ edition. Belmont, CA: Thompson Brooks/Cole.

Urquhart, F. A. 1960. The monarch butterfly. Toronto, ON: University of Toronto Press.

Urquhart, F.A., and Urquhart, N. R. 1976. The overwintering site of the eastern population of the monarch butterfly (Danaus plexippus; Danaidae) in southern Mexico. Journal of the Lepidopterists' Society 30: 153-158.

VanderWerf, E. A. 1993. Scales of habitat selection by foraging 'Elepaio in undisturbed and human-altered forests in Hawaii. The Condor 95: 980-989.

Venter, O., Brodeur, N. N., Nemiroff, L., Belland, B., Dolinsek, I. J., and Grant, J. W. 2006. Threats to endangered species in Canada. Bioscience, 56: 903-910.

Wäckers, F. L., Van Rijn, P. C. and Heimpel, G. E. 2008. Honeydew as a food source for natural enemies: making the best of a bad meal?. Biological Control, 45: 176-184.

Wassenaar, L. I., and Hobson, K. A. 1998. Natal origins of migratory monarch butterflies at wintering colonies in Mexico: New isotopic evidence. Proceedings of the National Academy of Sciences of the United States of America 95: 15436-15439.

Weldon, A. J., and Haddad, N. M. 2005. The effects of patch size on indigo buntings: Evidence for an ecological trap. Ecology 86: 1422-1431. 
Wilcove, D.S., Rothstein, D., Dubow, J., Phillips, A., and Losos, E. 1998. Quantifying threats to imperiled species in the United States. BioScience 45: 607-615.

Winter, M., Johnson, D. H., Shaffer, J. A., Donovan, T. M., and Svedarsky, W. D. 2006. Patch size and landscape effects on density and nesting success of grassland birds. Journal of Wildlife Management 70: 158-172.

Wisdom, M. J., Rowland, M. M., Wales, B. C., Hemstrom, M. A., Hann, W. J., Raphael, M. G., Holthausen, R. S., Gravenmier, R. A., and Rich, T. D. 2002. Modeled effects of sagebrush-steppe restoration on greater sage-grouse in the interior Columbia Basin, U.S.A. Conservation Biology 16: 1223-1231.

Zalucki, M. P. 1982. Temperature and rate of development in Danaus plexippus L. and D. chrysippus L. (Lepidoptera: Nymphalidae). Journal of Australian Entomological Society 21: $241-246$.

Zalucki, M.P., and Kitching, R. L. 1982a. Dynamics of oviposition in Danaus plexippus (Insecta: Lepidoptera) on milkweed, Asclepias spp. Journal of Zoology 198:103-116.

Zalucki, M.P., and Kitching, R. L. 1982b. Temporal and spatial variation of mortality in field populations of Danaus plexippus L. and D. chrysippus L. larvae (Lepidoptera: Nymphaidae). Oecologia 53: 201-207.

Zalucki, M. P., and Kitching, R. L. 1984. The dynamics of adult Danaus plexippus L. (Danaidae) within patches of its food plant, Asclepias spp. Journal of the Lepidopterists' Society 38: 209-219.

Zalucki, M. P., and Lammers, J. H. 2010. Dispersal and egg shortfall in monarch butterflies: what happens when the matrix is cleaned up? Ecological Entomology 35: 84-91. 
Zalucki, M. P., and Suzuki, Y. 1987. Milkweed patch quality, adult population structure, and egg laying in the monarch butterfly. Journal of the Lepidopterists' Society 41: 13-22.

Zaya, D. N., Pearse, I. S., and Spyreas G. 2017. Long-term trends in midwestern milkweed abundance and their relevance to monarch butterfly declines. BioScience. In press, doi:10.1093/biosci/biw186

Zoebelein, G. 1956. Der Honigtau als Nahrung der Insekten. Zeitschrift für Angewandte Entomologie 38: 369-416. 


\section{APPENDIX}

Table A-1. Results of AIC model comparisons, modeling egg density (eggs/milkweed using an offset) in response to multiple fixed predictors and random effect of patch ID. All models included in the model selection are shown (number of patches sampled $=111$ total; $2015: \mathrm{n}=$ 43; 2016: $n=68)$.

\begin{tabular}{|c|c|c|c|c|c|c|}
\hline Model & Fixed effect terms & $\mathrm{AIC}$ & $\triangle \mathrm{AIC}$ & $w$ & I & $\mathrm{K}$ \\
\hline 1 & $\begin{array}{l}\text { Julian date + year + landscape + patch size + } \\
\text { milkweed density + landscape:patch size }\end{array}$ & 2952.8 & 0.0 & 0.99 & 1.0 & 13 \\
\hline 2 & $\begin{array}{l}\text { Julian date }+ \text { year }+ \text { landscape }+ \text { patch size }+ \\
\text { landscape:patch size }\end{array}$ & 2962.5 & 9.7 & 0.01 & 0.008 & 12 \\
\hline 3 & $\begin{array}{l}\text { Julian date + year + landscape }+ \text { patch size }+ \\
\text { milkweed density }\end{array}$ & 3000.8 & 47.4 & 0 & 0 & 9 \\
\hline 4 & $\begin{array}{l}\text { Julian date }+ \text { year }+ \text { patch size }+ \text { milkweed } \\
\text { density }\end{array}$ & 3002.1 & 49.3 & 0 & 0 & 6 \\
\hline 5 & Julian date + year + patch size & 3008.2 & 55.4 & 0 & 0 & 6 \\
\hline 6 & $\begin{array}{l}\text { Julian date + year + landscape + milkweed } \\
\text { density }\end{array}$ & 3050.5 & 97.7 & 0 & 0 & 7 \\
\hline 7 & Julian date + year + landscape & 3054.5 & 101.7 & 0 & 0 & 6 \\
\hline 8 & Julian date + year + milkweed density & 3067.3 & 114.5 & 0 & 0 & 5 \\
\hline
\end{tabular}


Table A-2. Results of AIC model comparisons, modeling invertebrate predator abundance in response to multiple fixed predictors and random effect of patch ID. All models included in the model selection are shown (number of patches sampled $=86$ total; $2015: \mathrm{n}=18 ; 2016: \mathrm{n}=68$ ).

\begin{tabular}{|c|l|c|c|c|c|c|}
\hline Model & \multicolumn{1}{|c|}{ Fixed effect terms } & AIC & $\Delta$ AIC & $w$ & $I$ & $\mathrm{~K}$ \\
\hline 1 & Julian date + year + patch size & 2869.9 & 0.0 & 0.57 & 1.0 & 6 \\
\hline 2 & Julian date + year + landscape type + patch size & 2872.1 & 2.2 & 0.17 & 0.3 & 8 \\
\hline 3 & Julian date + year + patch size + milkweed density & 2872.7 & 2.8 & 0.11 & 0.2 & 7 \\
\hline 4 & Julian date + year + landscape type + patch size + & 2873.2 & 3.3 & 0.09 & 0.2 & 9 \\
& milkweed density & & & & & \\
\hline 5 & Julian date + year + milkweed density & 2877.1 & 7.2 & 0.01 & 0.03 & 5 \\
\hline 6 & Julian date + year + landscape type & 2877.6 & 7.7 & 0.01 & 0.02 & 6 \\
\hline 7 & Julian date + year + landscape type + milkweed & 2879.7 & 9.8 & 0.00 & 0.00 & 7 \\
& density & & & 7 & \\
\hline
\end{tabular}


Table A-3. Results of AIC model comparisons, modeling invertebrate predator diversity in response to multiple fixed predictors and random effect of patch ID. All models included in the model selection are shown (number of patches sampled $=86$ total; $2015: \mathrm{n}=18 ; 2016: \mathrm{n}=68$ ).

\begin{tabular}{|c|l|c|c|c|c|c|}
\hline Model & \multicolumn{1}{|c|}{ Fixed effect terms } & AIC & $\Delta \mathrm{AIC}$ & $w$ & $I$ & $\mathrm{~K}$ \\
\hline 1 & Julian date + year + landscape type & 754.8 & 0.0 & 0.29 & 1.0 & 6 \\
\hline 2 & Julian date + year + milkweed density & 755.1 & 0.31 & 0.25 & 0.86 & 5 \\
\hline 3 & Julian date + year + patch size & 755.3 & 0.57 & 0.22 & 0.75 & 6 \\
\hline 4 & Julian date + year + landscape type + milkweed & 756.9 & 2.11 & 0.10 & 0.35 & 7 \\
& density & & & & & \\
\hline 5 & Julian date + year + milkweed density + patch size & 757.4 & 2.67 & 0.08 & 0.26 & 7 \\
\hline 6 & Julian date + year + landscape type + patch size & 757.9 & 3.14 & 0.06 & 0.21 & 8 \\
\hline 7 & Julian date + year + landscape type + patch size + & 760.1 & 5.29 & 0.02 & 0.07 & 9 \\
& milkweed density & & & & & \\
\hline
\end{tabular}


Table A-4. Results of AIC model comparisons, modeling parasitoid abundance in response to multiple fixed predictors and random effect of patch ID. All models included in the model selection are shown (number of patches sampled $=86$ total; 2015: $n=18 ; 2016: n=68$ ).

\begin{tabular}{|c|l|c|c|c|c|c|}
\hline Model & \multicolumn{1}{|c|}{ Fixed effect terms } & AIC & $\Delta$ AIC & $w$ & $I$ & $\mathrm{~K}$ \\
\hline 1 & Julian date + year + landscape type & 1226.7 & 0.0 & 0.45 & 1.0 & 6 \\
\hline 2 & Julian date + year + landscape type + patch size & 1228.8 & 2.07 & 0.18 & 0.4 & 8 \\
\hline 3 & Julian date + year + patch size + milkweed density & 1229.2 & 2.53 & 0.14 & 0.3 & 7 \\
\hline 4 & Julian date + year + landscape type + patch size + & 1229.3 & 2.64 & 0.11 & 0.3 & 9 \\
& milkweed density & & & & & \\
\hline 5 & Julian date + year + milkweed density & 1231.1 & 4.42 & 0.04 & 0.1 & 6 \\
\hline 6 & Julian date + year + landscape type & 1232.3 & 5.66 & 0.02 & 0.06 & 7 \\
\hline 7 & Julian date + year + landscape type + milkweed & 1233.2 & 6.51 & 0.02 & 0.04 & 5 \\
& density & & & & & \\
\hline
\end{tabular}


Table A-5. Results of AIC model comparisons, modeling parasitoid diversity in response to multiple fixed predictors and random effect of patch ID. All models included in the model selection are shown (number of patches sampled $=86$ total; 2015: $n=18 ; 2016: n=68$ ).

\begin{tabular}{|c|l|c|c|c|c|c|}
\hline Model & \multicolumn{1}{|c|}{ Fixed effect terms } & AIC & $\Delta$ AIC & $w$ & $I$ & $\mathrm{~K}$ \\
\hline 1 & Julian date + year + milkweed density & 550.9 & 0.0 & 0.31 & 1.0 & 5 \\
\hline 2 & Julian date + year + landscape type + patch size & 551.1 & 0.11 & 0.29 & 0.95 & 6 \\
\hline 3 & Julian date + year + patch size + milkweed density & 552.3 & 1.35 & 0.16 & 0.51 & 7 \\
\hline 4 & Julian date + year + landscape type + patch size + & 553.2 & 2.24 & 0.10 & 0.33 & 6 \\
& milkweed density & & & & & \\
\hline 5 & Julian date + year + milkweed density & 554.2 & 3.17 & 0.06 & 0.20 & 7 \\
\hline 6 & Julian date + year + landscape type & 554.8 & 3.76 & 0.05 & 0.15 & 8 \\
\hline 7 & Julian date + year + landscape type + milkweed & 556.0 & 5.04 & 0.03 & 0.08 & 9 \\
& density & & & & & \\
\hline
\end{tabular}


Table A-6. Results of AIC model comparisons, modeling OE infection rate in fifth instars in response to multiple fixed predictors and random effect of patch ID. All models included in the model selection are shown (number of $5^{\text {th }}$ instars sampled $=106$ total; $2015: n=45 ; 2016: n=$ 61).

\begin{tabular}{|c|l|c|c|c|c|c|}
\hline Model & \multicolumn{1}{|c|}{ Fixed effect terms } & AIC & $\Delta$ AIC & $w$ & $I$ & $\mathrm{~K}$ \\
\hline 1 & Julian date + year + landscape type + milkweed & 105.4 & 0.0 & 0.45 & 1.0 & 4 \\
& density & & & & \\
\hline 2 & Julian date + year + milkweed density & 107.7 & 2.17 & 0.15 & 0.34 & 6 \\
\hline 3 & Julian date + year + landscape type & 107.5 & 2.33 & 0.14 & 0.31 & 5 \\
\hline 4 & Julian date + year + patch size + milkweed density & 107.8 & 2.42 & 0.12 & 0.30 & 6 \\
\hline 5 & Julian date + year + patch size & 109.6 & 4.24 & 0.05 & 0.12 & 5 \\
\hline 6 & Julian date + year + landscape type + patch size + & 110.0 & 4.65 & 0.04 & 0.10 & 8 \\
& milkweed density & & & & \\
\hline 7 & Julian date + year + landscape type + patch size & 111.5 & 6.11 & 0.02 & 0.05 & 7 \\
\hline
\end{tabular}




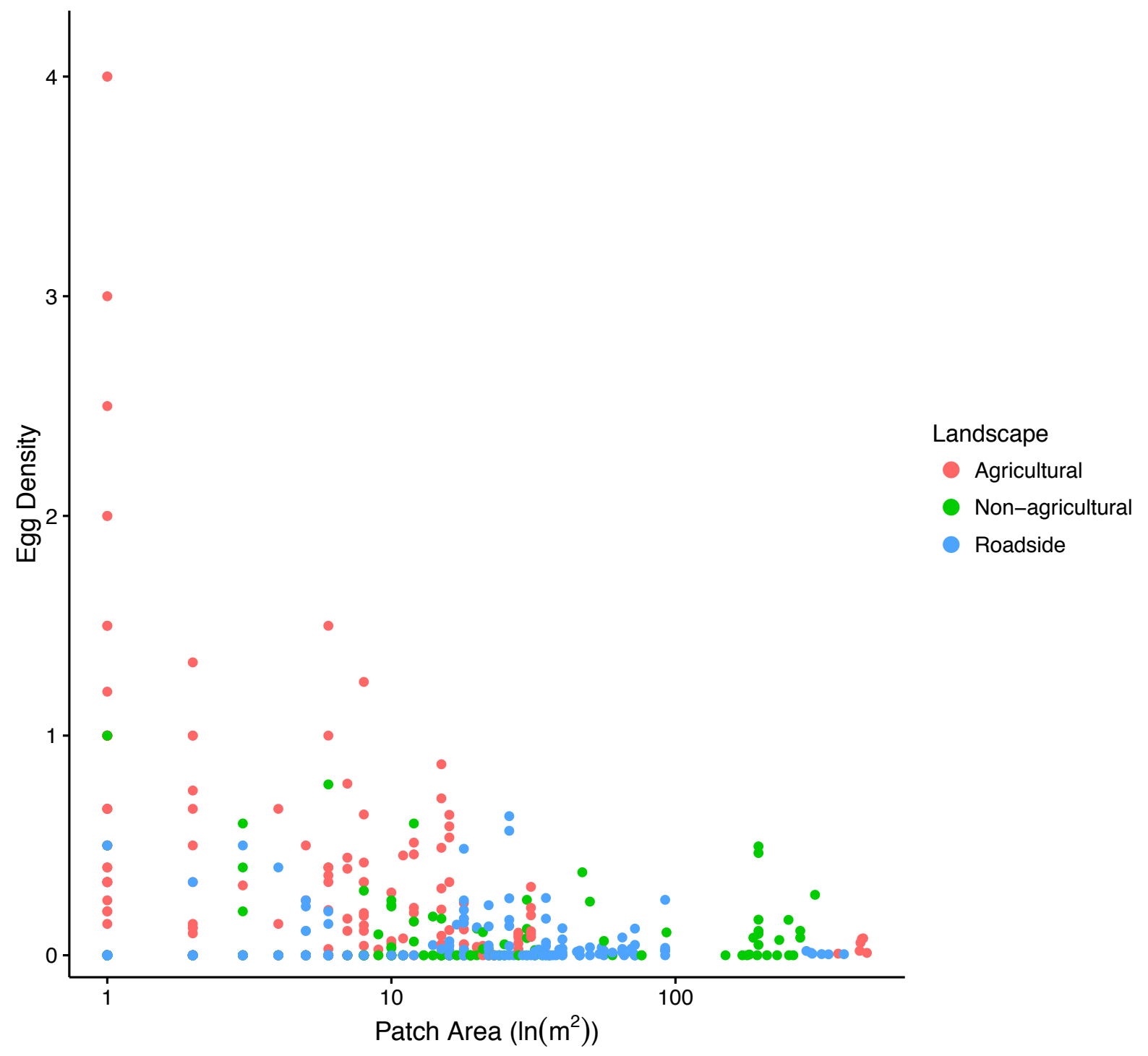

Figure A-1. Egg density per patch (number of eggs/number of milkweeds checked) and logtransformed patch area $\left(\mathrm{m}^{2}\right)$ by landscape type. 


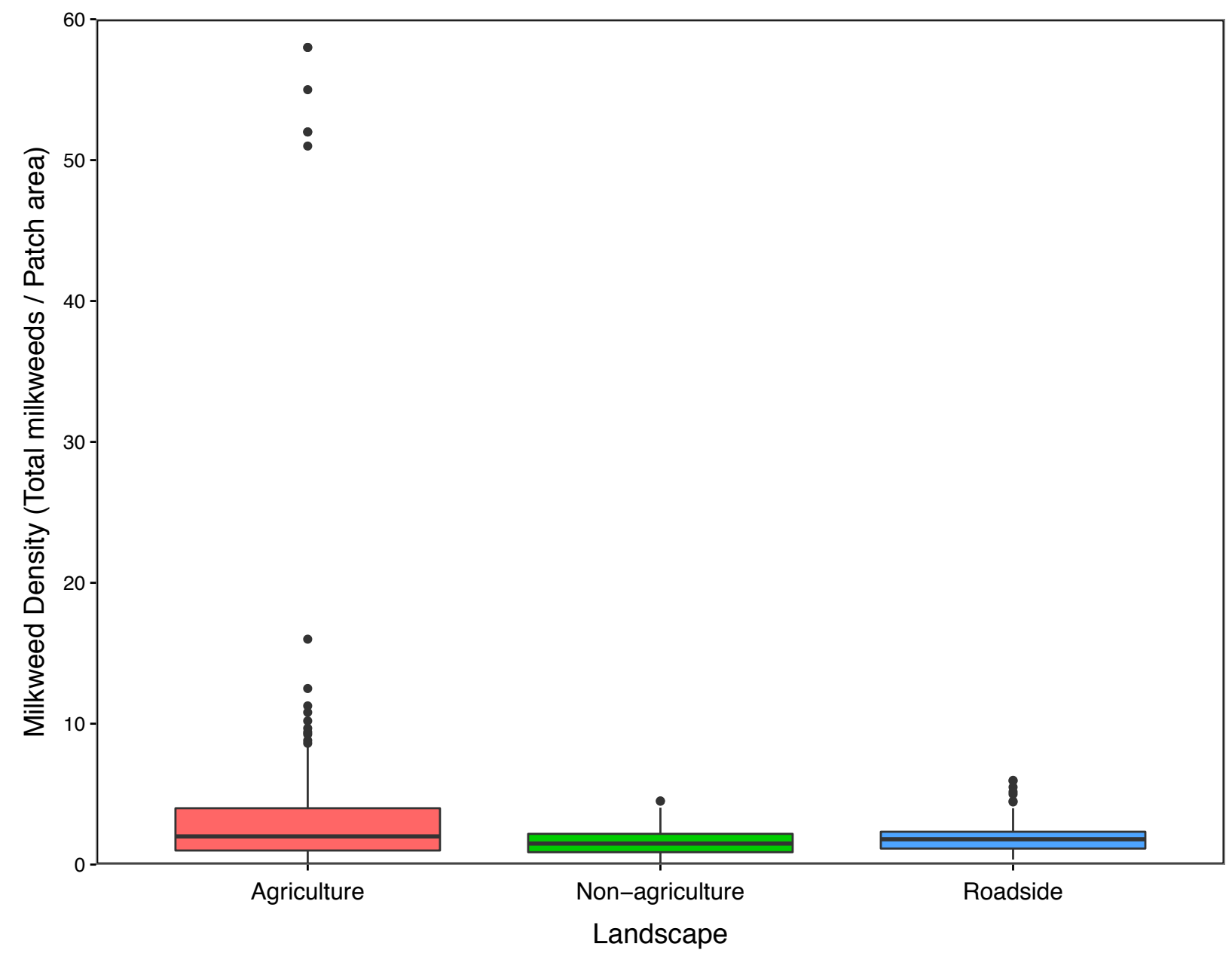

Figure A-2. Milkweed density per patch (total number of milkweed stems divided by the total area of the patch) in each landscape type (agriculture: $n=330$; non-agriculture: $n=162$;

roadside: $n=170$ ). Data are the same as Fig. 2 but with outliers included. Box and whiskers plot are composed of lower and higher quartiles (boxes), non-outlier ranges (whiskers), and medians (middle lines). Outliers are represented as dots. 


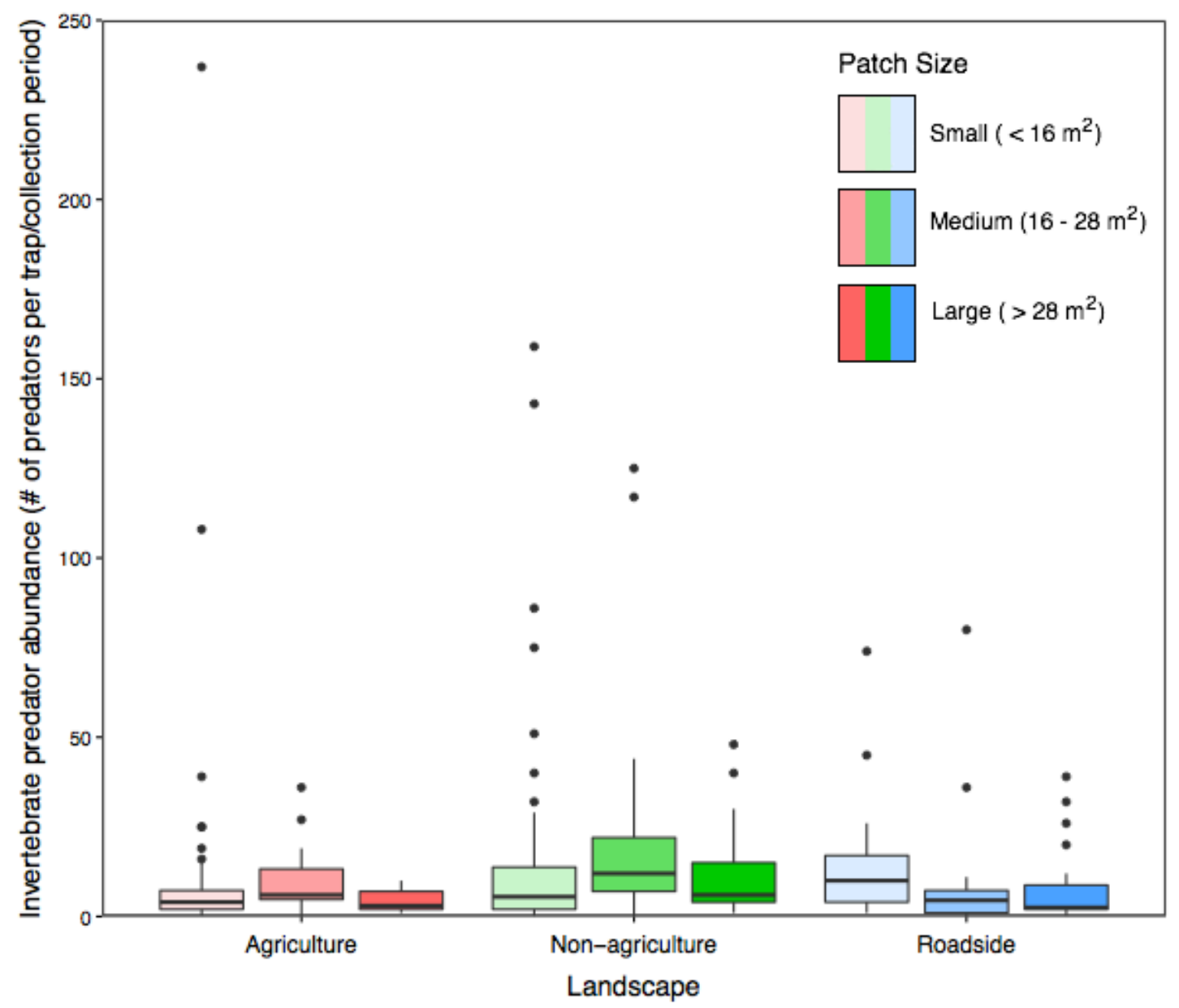

Figure A-3. Invertebrate predator abundance (number of predators per trap sampled every other week) per each patch size and landscape type (agriculture, non-agriculture, roadside). Data are the same as Fig. 4 but with outliers included. Box and whiskers plot are composed of lower and higher quartiles (boxes), non-outlier ranges (whiskers), and medians (middle lines). Outliers are represented as dots. 


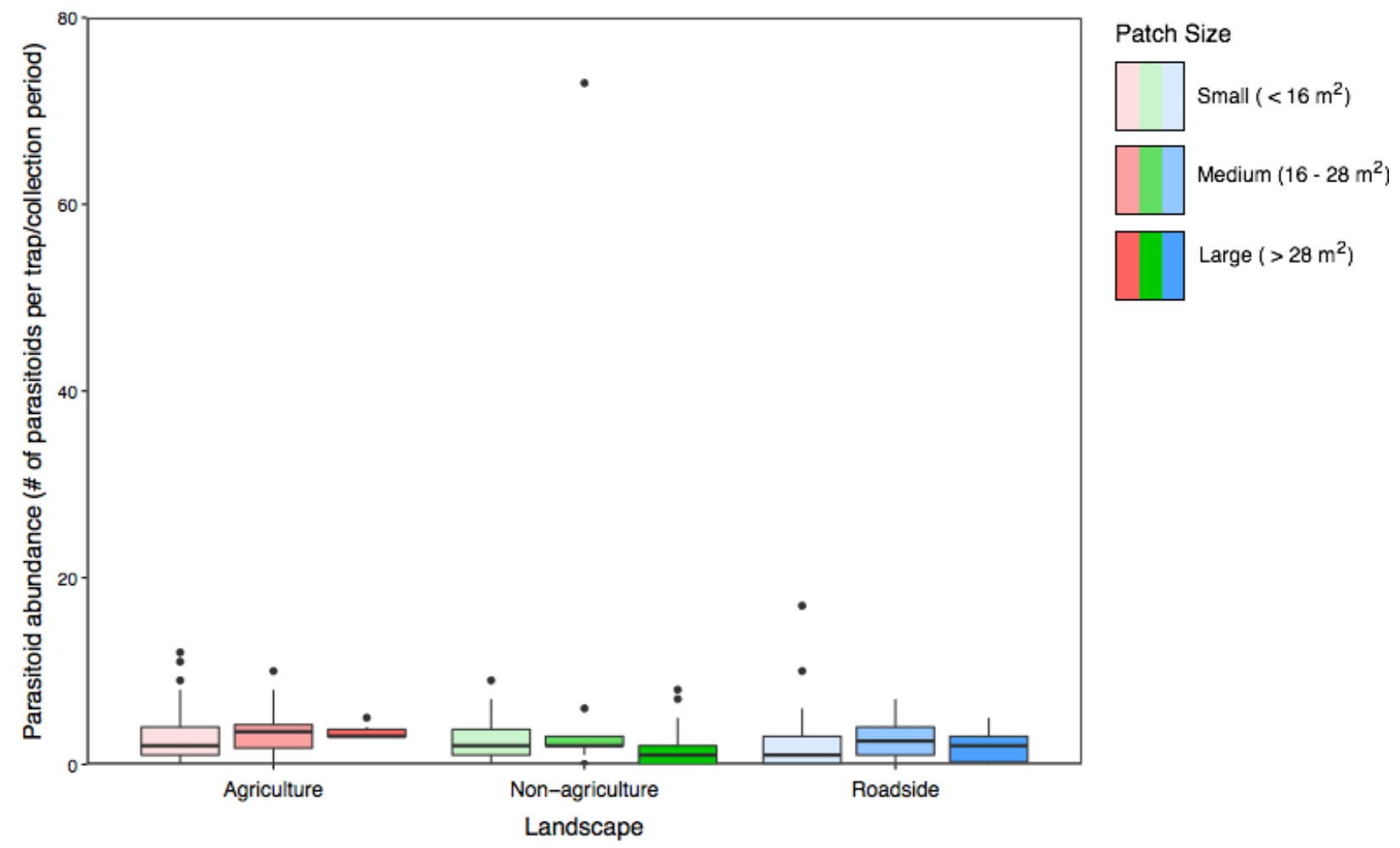

Figure A-4. Parasitoid abundance (number of parasitoids per trap sampled every other week) per each patch size and landscape type (agriculture, non-agriculture, roadside). Data are the same as Fig. 6 but with outliers included. Box and whiskers plot are composed of lower and higher quartiles (boxes), non-outlier ranges (whiskers), and medians (middle lines). Outliers are represented as dots. 